\title{
Electrophysiological Properties of Inferior Olive Neurons: A Compartmental Model
}

\author{
NICOLAS SCHWEIGHOFER, ${ }^{1}$ KENJI DOYA, ${ }^{1}$ AND MITSUO KAWATO ${ }^{1,2}$ \\ ${ }^{1}$ ERATO, Kawato Dynamic Brain Project, Japan Science and Technology Corporation; and ${ }^{2}$ ATR Human Information \\ Processing Research Laboratories, Kyoto 619-0288 Japan
}

\begin{abstract}
Schweighofer, Nicolas, Kenji Doya, and Mitsuo Kawato. Electrophysiological properties of inferior olive neurons: a compartmental model. J. Neurophysiol. 82: 804-817, 1999. As a step in exploring the functions of the inferior olive, we constructed a biophysical model of the olivary neurons to examine their unique electrophysiological properties. The model consists of two compartments to represent the known distribution of ionic currents across the cell membrane, as well as the dendritic location of the gap junctions and synaptic inputs. The somatic compartment includes a low-threshold calcium current $\left(I_{\mathrm{Ca}_{1} 1}\right)$, an anomalous inward rectifier current $\left(I_{\mathrm{h}}\right)$, a sodium current $\left(I_{\mathrm{Na}}\right)$, and a delayed rectifier potassium current $\left(I_{\mathrm{K} \_\mathrm{dr}}\right)$. The dendritic compartment contains a high-threshold calcium current $\left(I_{\mathrm{Ca}_{-} \mathrm{h}}\right)$, a calciumdependent potassium current $\left(I_{\mathrm{K}_{\mathrm{Ca}}}\right)$, and a current flowing into other cells through electrical coupling $\left(I_{\mathrm{c}}\right)$. First, kinetic parameters for these currents were set according to previously reported experimental data. Next, the remaining free parameters were determined to account for both static and spiking properties of single olivary neurons in vitro. We then performed a series of simulated pharmacological experiments using bifurcation analysis and extensive two-parameter searches. Consistent with previous studies, we quantitatively demonstrated the major role of $I_{\mathrm{Ca} \_1}$ in spiking excitability. In addition, $I_{\mathrm{h}}$ had an important modulatory role in the spike generation and period of oscillations, as previously suggested by Bal and McCormick. Finally, we investigated the role of electrical coupling in two coupled spiking cells. Depending on the coupling strength, the hyperpolarization level, and the $I_{\mathrm{Ca} \_}$and $I_{\mathrm{h}}$ modulation, the coupled cells had four different synchronization modes: the cells could be in-phase, phaseshifted, or anti-phase or could exhibit a complex desynchronized spiking mode. Hence these simulation results support the counterintuitive hypothesis that electrical coupling can desynchronize coupled inferior olive cells.
\end{abstract}

\section{N T R O D U C T I O N}

Cerebellar Purkinje cells, the sole output of the cerebellar cortex, receive two major inputs: the climbing fiber input, which originates from the inferior olive (IO), and the granule cell input, which relays information from the mossy fibers. Each Purkinje cell is innervated by one climbing fiber, and a single IO spike generates a single "complex spike" in a Purkinje cell. In contrast, a Purkinje cell receives $\leq 200,000$ granule cell inputs, which generate a high-frequency discharge ("simple spikes"). Because IO neurons fire at a very low frequency (at most 2 or 3 spikes within a second), there are comparatively few complex spikes. Although it is well known that simple spikes are involved in motor control, the role of

The costs of publication of this article were defrayed in part by the payment of page charges. The article must therefore be hereby marked "advertisement" in accordance with 18 U.S.C. Section 1734 solely to indicate this fact. complex spikes is more controversial (De Zeeuw et al. 1998; Simpson et al. 1996). The view that climbing fiber inputs function as detectors of control errors is well supported (e.g., Kitazawa et al. 1998; Kobayashi et al. 1998). However, it is still unclear whether climbing fibers exert a real-time influence on the targets of the Purkinje cells, and/or exert a short-term modulatory action on simple spike patterns, or induce longlasting changes in the potency of granule cell-Purkinje cell synapses.

IO neurons exhibit a number of unique electrophysiological properties. First, IO cells respond to both injection of depolarizing currents and release from hyperpolarization by generating, respectively, dendritic and somatic spikes (Llinás and Yarom 1981a). Second, in vitro IO cells can exhibit 4- to 8-Hz rhythmic activity (Bal and McCormick 1997; Benardo and Foster 1986; Llinás and Yarom 1986). This rhythmic activity can either take the form of subthreshold sinusoid-like oscillations or rhythmic generation of sodium spikes. Furthermore these oscillations can occur either spontaneously [in $\sim 10 \%$ of the cells recorded by Llinás and Yarom (1986); but Benardo and Foster (1986) reported a larger proportion of oscillating cells] or after harmaline or serotonin administration (Sugihara et al. 1995). Third, the cells are coupled by electrotonic gap junctions located on the dendrites (Llinás et al. 1974; Sotelo et al. 1974). Through the combined actions of the coupling between cells and the underlying rhythmicity of individual neurons, neighboring IO cells have been shown to fire with some rhythmicity in brain slices and acute preparations (Llinás and Yarom 1986; Sasaki et al. 1989). Yarom (1991) suggested that the IO is a network of damped oscillators that, when coupled, can generate sustained oscillations. However, the oscillatory behavior of IO cells in vivo is still under investigation because apparently random, rather than periodic, firing has been observed in behaving animals (Keating and Thach 1995). Thus it is probable that synaptic and modulatory inputs influence the oscillating behavior of single as well as group of coupled cells. Besides the very strong excitatory dendritic inputs (e.g., De Zeeuw et al. 1998), IO cells receive two types of inhibitory inputs: the first affects the excitability of the cell, whereas the second modulates the coupling strength between cells (Lang et al. 1996). Moreover, a strong serotonergic input to the IO from the midbrain raphe has been identified (Weiss and Pellet 1982).

Several studies have described the membrane currents of IO neurons and their influence on cell responses (Bal and McCormick 1997; Benardo and Foster 1986; Bleasel and Pettigrew 1994; Llinás and Yarom 1981b, 1986; Manor 1995; Manor et al. 1997; Ruigrok and Voogd 1985; Yarom and Llinás 1987). 
IO neurons exhibit two types of spatially distinct calcium currents: a low-threshold current $\left(I_{\mathrm{Ca}_{1}}\right)$ located in the soma and a high-threshold current $\left(I_{\mathrm{Ca}}\right)$ located in the dendrites (Llinás and Yarom 1981a,b). IO cells respond to both release from hyperpolarization and injection of depolarizing currents via these two calcium currents. The low-threshold calcium current has a window of conductance around the resting membrane potential, which causes the cell to be excited in response to hyperpolarizing current pulses. The high-threshold calcium current is noninactivating, which results in a prolonged plateau potential in response to depolarizing dendritic input. The calcium influx in the dendrites activates a calcium-dependent potassium current $\left(I_{\mathrm{K}_{-} \mathrm{Ca}}\right)$, which abruptly terminates the plateau potential after $\sim 30 \mathrm{~ms}$ (Llinás and Yarom 1981a). The inactivation of $I_{\mathrm{K}_{\mathrm{Ca}}}$ has a very long time constant (several hundred milliseconds), resulting in a long afterhyperpolarization (AHP). The AHP deinactivates the low-threshold calcium conductance and triggers a postinhibitory rebound. Furthermore, hyperpolarization activates an anomalous rectifying current (Bleasel and Pettigrew 1994; Yarom and Llinás 1987). Bal and McCormick (1997) recently argued that the h current $\left(I_{\mathrm{h}}\right)$, which originally was described in thalamocortical relay neurons (Huguenard and McCormick 1992), may account for many IO cell properties. They proposed that $I_{\mathrm{h}}$, which is activated at hyperpolarized potentials, contributes to the presence, amplitude, and frequency of the subthreshold oscillations. Finally, like most other neurons, IO cells can generate somatic sodium spikes (with the sodium current $I_{\mathrm{Na}}$ ) that are terminated by a delayed rectifier potassium current $\left(I_{\mathrm{K}_{\mathrm{dr}}}\right)$. However, a single spike is generated during the plateau potential, indicating a strong refractoriness of the sodium current (Llinás and Yarom 1981a).

The existence of electrical coupling between IO cell dendrites make voltage-clamp recording of individual IO cells arduous (Manor 1995). It is thus difficult to analyze the contribution of individual currents to the response of olivary neurons. Conductance-based models of neurons, however, if sufficiently constrained by biological data, may provide a means to test different hypotheses by systematically changing their parameters (e.g., maximal conductances of ionic channels). In the present study, we extended the single compartment model developed by Manor et al. (1997), which included only $I_{\mathrm{Ca}_{1}}$ and a leak current, and built a two-compartment model of IO neurons, where the first compartment represented the soma and the second compartment represented the lumped dendrites. The dendritic compartment permits us to account for the known dendritic location of the high-threshold calcium current, the gap junctions, and the synaptic inputs. We constrained the parameters of our model with experimental data whenever possible and reproduced many experimentally observed findings.

First, we further explored how the modulation of individual current conductances leads to different asymptotic electrical behaviors in single olivary neurons in vitro. Specifically, we quantitatively tested the influence of the low threshold calcium current $I_{\text {Ca_l } 1}$ and the $\mathrm{h}$ current $I_{\mathrm{h}}$ on single IO cell firing patterns. Consistent with previous experimental findings, we quantitatively demonstrated the major role of $I_{\mathrm{Ca} \_}$in spiking excitability. In addition, in line with the study of Bal and McCormick (1997), we found that $I_{\mathrm{h}}$ had an important modulatory role in the spike generation and period of oscillations.
Then we examined the role of electrical coupling on the spiking behavior of IO cells. Because IO cells were discovered to be extensively coupled by gap junctions (Llinás et al. 1974; Sotelo et al. 1974), researchers have been looking for the functional roles of the electrical coupling. In most neurophysiological studies, electrical coupling is thought to be responsible for the synchronization of groups of neurons. However, in several mathematical studies of simple coupled neuron models, anti-phase as well as irregular spiking have been observed (Abarbanel et al. 1996; Kawato et al. 1979; Sherman and Rinzel 1992). Thus, although counterintuitive, electrical coupling theoretically could desynchronize rather than synchronize coupled cells. In the present study, we found that two coupled IO cells could have different spiking modes depending on the coupling strength, the hyperpolarization level, and the modulation of $I_{\mathrm{Ca} 1}$ and $I_{\mathrm{h}}$ currents: the two cells could be in-phase, phase-shifted, or anti-phase or could exhibit a complex, desynchronized spiking mode. We discuss the robustness and significance of the desynchronization for the in vivo functioning of the IO in light of the known effect of serotonin on IO neurons.

\section{E T H O D S}

\section{General cell model}

The electrotonic properties of the two-compartment model (Fig. $1 A$ ) were determined by two morphological parameters (Pinsky and Rinzel 1994): the ratio of the somatic area to total surface area $(p)$ and the electrotonic coupling conductance between the two compartments $\left(g_{\text {int }}\right)$. For each compartment, the membrane potential $(V)$ changed according to

$$
C_{\mathrm{m}} \frac{\mathrm{d} V}{\mathrm{~d} t}=-\sum_{i} I_{i}+I_{\mathrm{app}}
$$

$C_{\mathrm{m}}$ is the membrane capacitance, $I_{\mathrm{app}}$ is the applied current (common to both compartments) and $\sum_{i} I_{i}$ accounts for the ionic currents, the current flowing out into the other compartment, and the current flowing through the gap junctions (currents in $\mu \mathrm{A} / \mathrm{cm}^{2}$ ).

\section{Somatic currents}

The somatic ionic currents included $I_{\mathrm{Ca} \_}, I_{\mathrm{h}}$, an inward sodium current $\left(I_{\mathrm{Na}}\right)$ and a delayed rectifier outward potassium current $\left(I_{\mathrm{K} \_\mathrm{dr}}\right)$, as well as the current flowing out into the dendrites $\left(I_{\mathrm{ds}}\right)$ and the leakage current $\left(I_{\mathrm{ls}}\right){ }^{1}$

$$
\sum_{i} I_{i}=I_{\mathrm{Ca} \_1}+I_{\mathrm{h}}+I_{\mathrm{Na}}+I_{\mathrm{K} \_\mathrm{dr}}+I_{\mathrm{ds}}+I_{\mathrm{ls}}
$$

To model these currents, we used data obtained from IO cells whenever possible; but when not available, we used experimentally derived data or models of similar currents from other neural systems. Manor (1995) quantified the activation and inactivation functions of $I_{\mathrm{Ca} \_\mathrm{l}}$ in the IO cell (see APPENDIX). $I_{\mathrm{h}}$ was modeled in thalamic relay neurons by Huguenard and McCormick (1992). The equation for $\mathrm{I}_{\mathrm{ds}}$ was obtained from Rush and Rinzel (1994), as was $I_{\mathrm{K} \text { dr }}$. Because a sodium current of the Hodgkin-Huxley type would generate several spikes during the plateau potential, whereas IO neurons normally only

\footnotetext{
${ }^{1}$ Yarom and Llinás (1987) demonstrated that the anomalous rectifying current consists of two parts: a time-dependent component and an instantaneous component. Due to the lack of a precise current model, we did not include the instantaneous component of the anomalous rectifying current in the present model.
} 
B
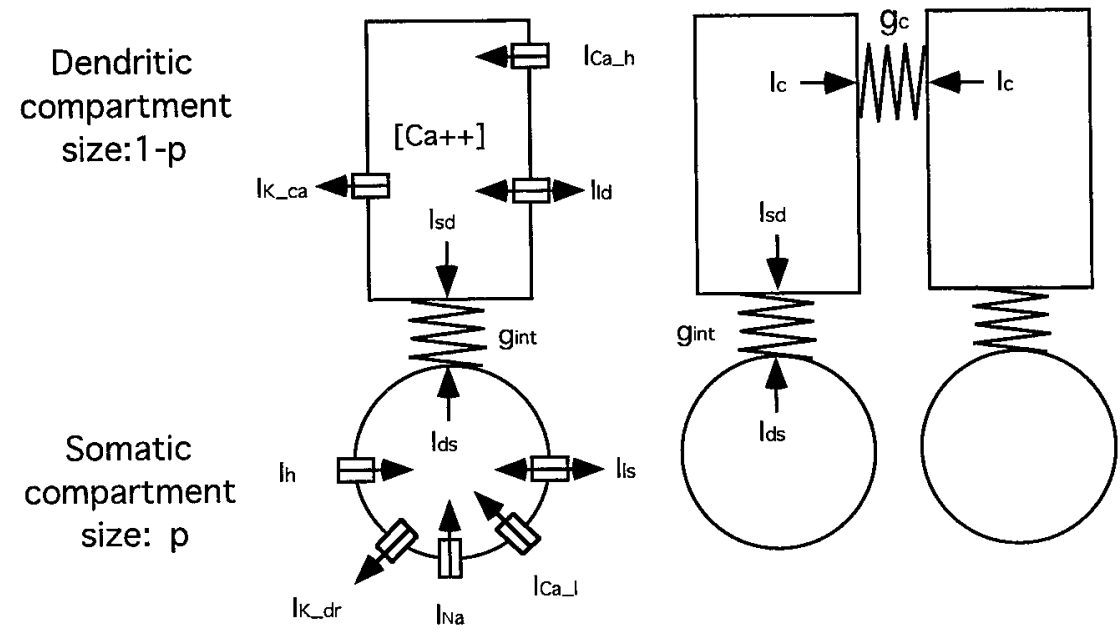

FIG. 1. Model of inferior olive (IO) neurons. A: 2-compartment biophysical model of an IO cell. Somatic ionic currents include a low-threshold calcium inward current $\left(I_{\mathrm{Ca} \__{1}}\right)$, an anomalous inward rectifier current $\left(I_{\mathrm{h}}\right)$, the Hodgkin-Huxley type inward sodium $\left(I_{\mathrm{Na}}\right)$ and outward delayed rectifier potassium $\left(I_{\mathrm{K} \text { dr }}\right)$ currents, the current flowing out into the dendritic compartment $\left(I_{\mathrm{ds}}\right)$, and a leakage current $\left(I_{\mathrm{ls}}\right)$. Dendritic currents include a highthreshold inward calcium current $\left(I_{\mathrm{Ca}_{-} \mathrm{h}}\right)$, an outward calcium-dependent potassium current $\left(I_{\mathrm{K}_{-} \mathrm{Ca}}\right)$, the current flowing into the somatic compartment $\left(I_{\mathrm{sd}}\right)$, and a leakage current $\left(I_{\mathrm{ld}}\right)$. Because the dendritic potassium Current $I_{\mathrm{K}_{-} \mathrm{Ca}}$ is calcium-dependent, $\mathrm{Ca}^{2+}$ concentration dynamics is included in the model. $g_{\text {int }}$ is the coupling conductance between the two compartments. $B: 2$ cells electrotonically coupled by a single hypothetical gap junction with maximal coupling conductance $g_{\mathrm{c}}$. Electrotonic coupling current between the cells is given by $I_{\mathrm{c}}$. generate a single spike, we adapted a new type of $I_{\mathrm{Na}}$ with a longlasting inactivation component. The somatic currents are given by

$$
\begin{gathered}
I_{\mathrm{Ca} \_1}=g_{\text {Ca } \_} k^{3} l\left(V \mathrm{~s}-V_{\mathrm{Ca}}\right) \\
I_{\mathrm{h}}=g_{\mathrm{h}} q\left(V \mathrm{~s}-V_{\mathrm{h}}\right) \\
I_{\mathrm{Na}}=g_{\mathrm{Na}} m_{\infty}(V \mathrm{~s})^{3} h\left(V \mathrm{~s}-V_{\mathrm{Na}}\right) \\
I_{\mathrm{K}_{-} \mathrm{dr}}=g_{\mathrm{K} \_\mathrm{dr}} n^{4}\left(V \mathrm{~s}-V_{\mathrm{K}}\right) \\
I_{\mathrm{ds}}=\left(g_{\text {int }} / p\right)\left(V \mathrm{~s}-V_{\mathrm{d}}\right) \\
I_{1 \mathrm{~s}}=g_{1 \mathrm{~s}}\left(V \mathrm{~s}-V_{1}\right)
\end{gathered}
$$

where $k, l, q, h$, and $n$ are activation and inactivation variables, the kinetics of which are described in the APPENDIX; $V_{\mathrm{s}}$ is the membrane potential of the soma and $V_{\mathrm{d}}$ is the membrane potential of the dendrite. $V_{\mathrm{Ca}}, V_{\mathrm{h}}, V_{\mathrm{Na}}$, and $V_{\mathrm{K}}$ are the reversal potentials of the sodium, potassium, calcium, and h currents, respectively (potentials in $\mathrm{mV}$ ); $g_{\mathrm{Ca} \_1}, g_{\mathrm{h}}, g_{\mathrm{Na}}, g_{\mathrm{K} \_\mathrm{dr}}$, and $g_{\mathrm{ls}}$ are maximal conductances (in $\mathrm{mS} / \mathrm{cm}^{2}$ ).

\section{Dendritic currents}

The dendritic ionic currents include $I_{\mathrm{Ca}_{\mathrm{h}}}, I_{\mathrm{K} \text { Ca }}$, the current flowing into the somatic compartment $\left(I_{\mathrm{sd}}\right)$, a leakage current $\left(I_{\mathrm{ld}}\right)$, and the current flowing into other cells through electrical coupling $\left(I_{\mathrm{c}}\right)$. Thus the dendritic currents are given by

$$
\sum_{i} I_{i}=I_{\mathrm{Ca}_{-} \mathrm{h}}+I_{\mathrm{K}_{-} \mathrm{Ca}}+I_{\mathrm{sd}}+I_{\mathrm{ld}}+I_{\mathrm{c}}
$$

Traub et al. (1991) modeled $I_{\mathrm{Ca} \_}, I_{\mathrm{K}_{\mathrm{Ca}}}$, and the dynamics of calcium concentration for CA3 neurons. Rush and Rinzel (1994) described the expression of $I_{\text {sd }}$ for a two-compartment cell model. Finally, like all gap junctions between all mammalian cells thus far evaluated (Moreno et al. 1994), the conductance of $I_{\mathrm{c}}$ has been shown recently to be voltage dependent (Kogan and Yarom 1997). Precise voltagedependency curves are not yet available for the gap junction protein connexin36, which is important for the IO (Condorelli et al. 1998). Therefore we adopted the general voltage-dependency model from Benett and Versedis (1992), and we set the parameters according to the activity of the gap junction protein connexin43 (Moreno et al. 1994). The number of gap junctions is presumably between 5 and 20 for any pair of IO cells (De Zeeuw et al. 1996). However, as we modeled only a single dendritic compartment per cell, an agglomerate of gap junctions between two cells can be represented by a single conductance, $g_{\mathrm{c}}{ }^{2}$ Thus the dendritic ionic currents are given by

$$
\begin{gathered}
I_{\mathrm{Ca}_{-} \mathrm{h}}=g_{\mathrm{Ca}_{-} \mathrm{h}} r^{2}\left(V_{\mathrm{d}}-V_{\mathrm{Ca}}\right) \\
I_{\mathrm{K}_{-} \mathrm{Ca}}=g_{\mathrm{K}_{-} \mathrm{Ca}} s\left(V_{\mathrm{d}}-V_{\mathrm{K}}\right) \\
I_{\mathrm{ld}}=g_{\text {ld }}\left(V_{\mathrm{d}}-V_{1}\right) \\
I_{\mathrm{sd}}=\left[g_{\text {int }} /(1-p)\right]\left(V_{\mathrm{d}}-V_{\mathrm{s}}\right) \\
I_{\mathrm{c}}=g_{\mathrm{c}} f\left(V_{\mathrm{d}}-V_{\mathrm{de}}\right)\left(V_{\mathrm{d}}-V_{\mathrm{de}}\right)
\end{gathered}
$$

where $r$ and $s$ are activation and inactivation variables, respectively (see APPENDIX); $f$ represents the transjunctional voltage dependence of the gap junction conductance; $V_{\mathrm{d}}$ is the dendritic membrane potential of the cell; $V_{\mathrm{de}}$ is the dendritic membrane potential of another IO cell in electrotonic contact with the cell; $g_{\mathrm{Ca} \_\mathrm{h}}, g_{\mathrm{K} \_\mathrm{Ca}}, g_{\mathrm{ld}}$, and $g_{\mathrm{c}}$ are maximal conductances.

\section{Modeling a "standard" cell}

A neural model can have a wide variety of responses when large parameter ranges are considered (Rinzel and Ermentrout 1989). Our model of IO neurons, although simplified, contains a large number of parameters. Consequently whenever possible, physiologically plausible ranges of parameters are first taken into account (see Table 1). Moreover we use typical values for sodium, potassium, and calcium reversal potentials and membrane capacitance: $V_{\mathrm{Na}}=55 \mathrm{mV}, V_{\mathrm{K}}=$ $-75 \mathrm{mV}$, and $V_{\mathrm{Ca}}=120 \mathrm{mV}$ and $C_{\mathrm{m}}=1 \mu \mathrm{F} / \mathrm{cm}^{2}$, respectively. We took the reversal potential of the $\mathrm{h}$ current to be $V_{\mathrm{h}}=-43 \mathrm{mV}$, as reported by Huguenard and McCormick (1992). The remaining unknown parameters were investigated using the simulation software package XPPAUT (Ermentrout 1997) to integrate the equations of the system. We developed a "standard" cell that possessed most of the known electrophysiological properties of IO cells by taking a priori ranges of parameters into account when available.

\footnotetext{
${ }^{2}$ The electrotonic coupling conductance $\mathrm{g}_{\text {int }}$ between the somatic and dendritic compartments mathematically represents the inverse of the cell's cytoplasmic resistivity. The electrical coupling conductance $\mathrm{g}_{\mathrm{c}}$ between the cells reflects the strength of the intercellular electrical coupling. Although these two types of coupling are very different physiologically, in two-compartment models they are represented similarly, by the coupling conductances $\mathrm{g}_{\text {int }}$ and $\mathrm{g}_{\mathrm{c}}$. However, to account for the cell integrity, the value of the former must be much higher than the value of the latter.
} 
TABLE 1. A priori ranges of several parameters

\begin{tabular}{lll}
\hline \hline \multicolumn{1}{c}{ Parameter } & Range & \multicolumn{1}{c}{ Source } \\
\hline$p$ & $0.1-0.4$ & $\begin{array}{l}\text { Manor (1995) } \\
\text { Pinsky and Rinzel (1994) } \\
g_{\text {int }}, \mathrm{mS} / \mathrm{cm}^{2}\end{array}$ \\
& $0.1-3$ & $\begin{array}{l}\text { Booth et al. (1997) } \\
\text { Mainen and Sejnowski (1996) }\end{array}$ \\
$g_{\mathrm{c}}, \mathrm{mS} / \mathrm{cm}^{2}$ & $g_{\mathrm{c}}<g_{\text {int }}$ & Manor (1995) \\
$g_{\text {Ca_l }}, \mathrm{mS} / \mathrm{cm}^{2}$ & $0.1-3$ & Manor et al. (1997) \\
$g_{\text {ls }}$ and $g_{\text {ld }}, \mathrm{mS} / \mathrm{cm}^{2}$ & $<0.5$ & Manor et al. (1997) \\
\hline
\end{tabular}

\section{Sensitivity analysis}

We tracked the stationary and periodic solutions of the system with a change in a parameter (such as the input current) using the bifurcation analysis software AUTO (Doedel 1981). AUTO also allowed us to compute the frequency of oscillations, detect the bifurcation of solutions, and track the bifurcation points (e.g., the onset of oscillations) in two-dimensional parameter space. Because it was impossible to track the bifurcation of periodic orbits with this software (e.g., points for which 2 periodic solutions, such as subthreshold oscillations and spontaneous spiking, coalesce), we developed a custom simulator based on the integration simulation package CVODE (Cohen and Hindmarsh 1994). Thus we could explore spiking behaviors when one or two parameters were varied. By numerically integrating the model equations with different parameter values, we uncovered several asymptotic cell response domains: return to rest (R) after a period of transients, spontaneous subthreshold oscillations (SO), spontaneous somatic spiking (SS), spontaneous dendritic spiking (DS). In some cases, the cell could stay in different symptotic states depending on the initial conditions: the cell was then described bistable, and in this case the domains were overlapping. ${ }^{3}$ For instance, when the SO domain overlapped with SS, the cell behavior was denoted to be $\mathrm{SS} / \mathrm{SO}$ bistable. Note that in the sensitivity analysis graphs, we plotted both the results obtained with AUTO (for the domain of oscillatory behavior emerging from rest) and the results obtained with our simulator (for the other domains).

\section{Analyzing the responses of two coupled cells}

We examined the behavior of two coupled cells when $g_{c}$ varied (Fig. 1B). To describe the extent of synchronization between two identical cells that receive identical inputs, we computed the average "distance" $D\left(\tau, g_{\mathrm{c}}\right)$, in millivolts, between the somatic membrane potentials (Abarbanel et al. 1996). This measure is essentially the root mean square difference between the somatic membrane potentials of the two cells, $V_{\mathrm{s} 1}$ and $V_{\mathrm{s} 2}$, with a time shift $\tau$. The time shift between the activities of the neurons is necessary to "align" the neurons' responses. The average distance is mathematically defined by

$$
D\left(\tau, g_{\mathrm{c}}\right)=\sqrt{\frac{1}{N} \sum_{t=1}^{N}\left[V_{\mathrm{s} 1}(t)-V_{\mathrm{s} 2}(t+\tau)\right]^{2}}
$$

where $N$ is the total number of time steps (1 time step was $1 \mathrm{~ms}$ ). As in Abarbanel et al., we plot $D\left(\tau_{\min }, g_{\mathrm{c}}\right)$, which is the distance for the

\footnotetext{
${ }^{3}$ To detect these cases, current pulses of 21 different intensities (from -8 $\mu \mathrm{A} / \mathrm{cm}^{2}$ to $+8 \mu \mathrm{A} / \mathrm{cm}^{2}$, for $50 \mathrm{~ms}$ ) were injected into the cell's soma. We considered the cell to be bi-stable if at least one current injection could generate sustained spiking (when the cell was not spontaneously spiking before the current injection) or stop spiking (when the cell was spontaneously spiking before the current injection). Note that this method introduces a resolution limit of $0.8 \mu \mathrm{A} / \mathrm{cm}^{2}$, which corresponds to $0.08 \mathrm{nA}$ only for a total cell surface of $10,000 \mu \mathrm{m}^{2}$. It is therefore possible that we missed some small ranges of bi-stability. However, these very small bi-stability ranges would have negligible physiological consequences.
}

time shift $\tau_{\min }$ that yields the minimum value of $D\left(\tau, g_{\mathrm{c}}\right)$, for fixed coupling. For instance, if the neurons are anti-phase, the distance $D\left(\tau_{\min }, g_{\mathrm{c}}\right)$ is zero and the time shift $\tau_{\min }$ equals to half a period. Initially a perturbing stimulus input was given at $t=1 \mathrm{~s}$ in cell 1 . The distance was then computed over $10 \mathrm{~s}$, from $t=5 \mathrm{~s}$ to ignore the transients.

\section{RES ULTS}

\section{Standard cell}

Using the following parameter values (conductances in $\mathrm{mS} /$ $\mathrm{cm}^{2}$ ), soma: $g_{\mathrm{Na}}=70, g_{\mathrm{K} \_\mathrm{dr}}=18, g_{\mathrm{CA} 1}=1.0$, and $g_{\mathrm{h}}=1.5$; dendrite: $g_{\mathrm{Ca} \mathrm{h}}=4.0$ and $g_{\mathrm{K} \_\mathrm{Ca}}=35$; leak: $g_{\text {ls }}=g_{\text {ld }}=0.015$ and $v_{1}=-10 \mathrm{mV}$; cell morphology: $g_{\text {int }}=0.13$ and $p=0.20$, data from our standard cell model were consistent with many reported experimental findings from actual IO neurons.

STEADY-STATE PROPERTIES. The membrane potential with no input current $\left(I_{\text {app }}=0 \mu \mathrm{A} / \mathrm{cm}^{2}\right)$ was $-57 \mathrm{mV}$, whereas the input resistance derived from the voltage-current curve was 36 $\mathrm{M} \Omega$. When $I_{\mathrm{app}}=-5 \mu \mathrm{A} / \mathrm{cm}^{2}$, the potential was $-80.3 \mathrm{mV}$ and the input resistance was $14 \mathrm{M} \Omega$, reflecting the effect of the h current. When $I_{\mathrm{app}}=+5 \mu \mathrm{A} / \mathrm{cm}^{2}$, the membrane potential was $-46 \mathrm{mV}$ and the input resistance was only $10 \mathrm{M} \Omega$ because of the effect of the delayed rectifier current. These steady-state values are in agreement with published experimental data (see for instance Table 1 in Llinás and Yarom 1981a; Fig. 1A in Yarom and Llinás 1987; Manor 1995). Note that $1 \mu \mathrm{A} / \mathrm{cm}^{2}$ corresponds to $0.1 \mathrm{nA}$ for a total cell surface of $10,000 \mu \mathrm{m}^{2}$.

DEPOLARIZING CURRENT INPUT. We injected depolarizing step currents of 50-ms duration, beginning at $t=200 \mathrm{~ms}$ in the cell at rest (Fig. 2). When the injected current intensity was $>3$ $\mu \mathrm{A} / \mathrm{cm}^{2}$, the cell first responded with a somatic sodium spike immediately followed by a dendritic calcium plateau potential (Fig. 2A), which lasted for $\sim 35 \mathrm{~ms}$. The calcium plateau potential, due to activation of $I_{\mathrm{Ca} \text { h }}$, created a large calcium ion influx in the dendrites, which in turn activated $I_{\mathrm{K}_{\mathrm{Ca}}}$ (Fig. 2C). This eventually terminated the plateau potential and created a large, long-lasting AHP $\sim 13 \mathrm{mV}$ below the resting membrane potential. At the offset of the dendritic spike, $I_{\mathrm{Ca} \text { h }}, I_{\mathrm{Ca} 1}$, and $I_{\mathrm{h}}$ are all completely inactivated (as are $I_{\mathrm{Na}}$ and $I_{\mathrm{K} \text { dr }}$ ). Thus the only nonzero current is $I_{\mathrm{K} \_C a}$. Because this current is driven by relatively slow dendritic calcium dynamics and possesses a long inactivation time constant, the AHP is dominated by $I_{\mathrm{K} C a}$. Note that even though the conductance of $I_{\mathrm{K} \text { Ca }}$ is high, the amplitude of $I_{\mathrm{K}_{-} \mathrm{Ca}}$ is small during the AHP because the membrane potential is close to the potassium reversal potential. The AHP terminated sharply after $\sim 300 \mathrm{~ms}$ due to rebound excitation, which is consistent with published data (see Fig. 7A in Llinás and Yarom 1981b). The time courses of the somatic currents (Fig. 2B) revealed that the AHP termination is initially due to the activation of $I_{h}$, which increases the membrane potential. Then when the soma is sufficiently depolarized, $I_{\mathrm{Ca} \_1}$ starts to be activated, which results in the rebound of excitation.

HYPERPOLARIZING CURRENT INPUT. We then studied the response of the standard cell model to a hyperpolarizing current pulse $(t=500 \mathrm{~ms}$, duration $=100 \mathrm{~ms}$, intensity $=-1.5$ $\mu \mathrm{A} / \mathrm{cm}^{2}$ ) superimposed on different tonic hyperpolarizing currents $\left(I_{\text {app }}\right)$. When $I_{\text {app }}=0 \mu \mathrm{A} / \mathrm{cm}^{2}$, the activation of the low-threshold calcium conductance, as well as the recovery of 
A
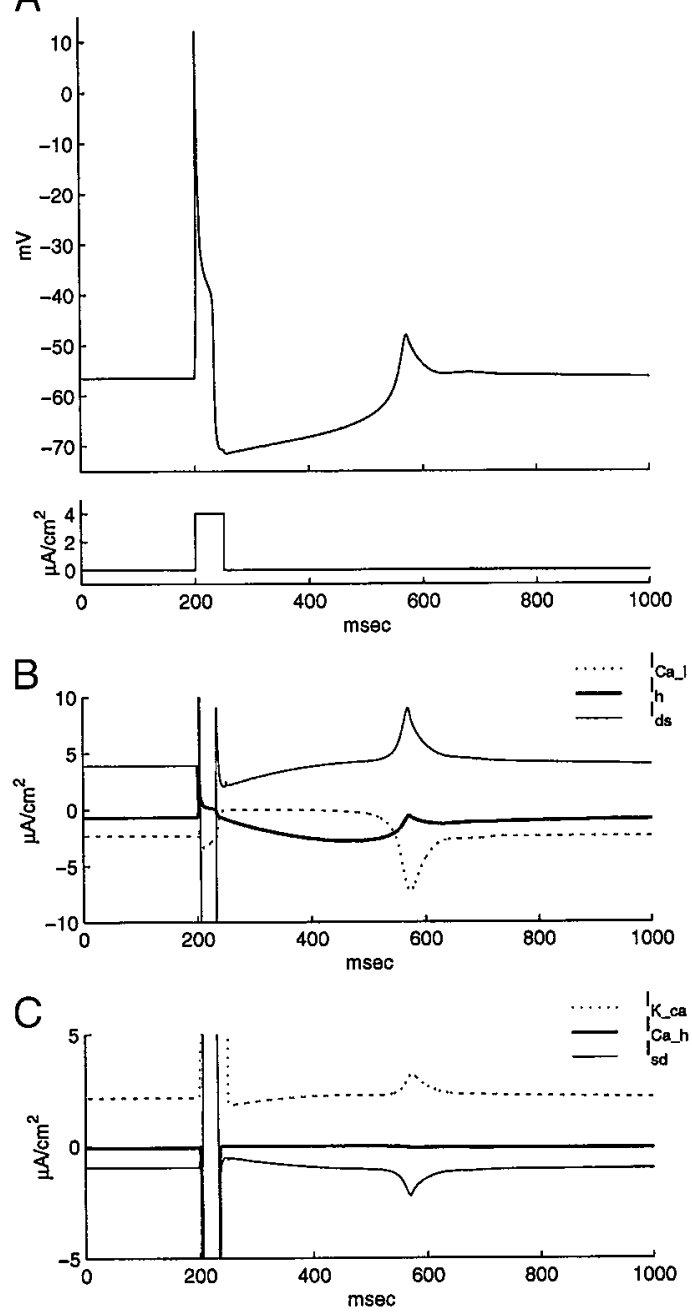

FIG. 2. Responses of an IO cell model to a dendritic current pulse (intensity: $8 \mu \mathrm{A} / \mathrm{cm}^{2}$, duration: $50 \mathrm{~ms}$ ). $A$ : somatic membrane potential: the cell $1 \mathrm{st}$ responded with a somatic sodium spike immediately followed by a dendritic calcium plateau potential ensued by a long-lasting after-hyperpolarization, which is terminated by a rebound potential. $B$ : somatic currents; $C$ : dendritic currents (note difference in ordinate scale between $B$ and $C$ ).

$I_{\mathrm{h}}$, during the hyperpolarizing step created a rebound sufficient to generate a sodium spike (Fig. 3A). This is consistent with previous experimental data (Bal and McCormick 1997; see their Fig. 2 for instance). $I_{\mathrm{Ca}_{1} 1}$ then became inactivated and $I_{\mathrm{Ca} \_\mathrm{h}}$ became activated to a moderate degree. The calcium influx in the dendritic compartment resulted in the $I_{\mathrm{K} \_\mathrm{Ca}}$ activation, creating an AHP. The cycle began again, and another spike was generated. After the second spike, however, $I_{\mathrm{Ca} \_1}$ was no longer sufficiently activated to bring the membrane potential above threshold and only a few more subthreshold oscillations followed. Thus the standard cell was a damped oscillator, as reported by Lampl and Yarom (1997). When a tonic bias hyperpolarizing current $I_{\text {app }}=-0.5 \mu \mathrm{A} / \mathrm{cm}^{2}$ was maintained before the current pulse, the cell was SO (Fig. $3 B$ ). The cell fired a burst of six spikes after the pulse. When the bias was $I_{\text {app }}=-1.0 \mu \mathrm{A} / \mathrm{cm}^{2}$ (Fig. $3 C$ ), the cell generated two sodium spikes in response to the current pulse. Finally, when the bias was $I_{\text {app }}=-1.5 \mu \mathrm{A} / \mathrm{cm}^{2}$ (Fig. 3D), only one spike was generated and the oscillations were rapidly damped.

\section{Parameter sensitivity analysis}

BIFURCATION ANALYSIS. The steady-state cell responses at different hyperpolarized membrane potentials can be predicted from a bifurcation diagram plotting the minimum and maximum values of the somatic membrane potential for $I_{\text {app }}$. The cell had a stable steady state for all $I_{\text {app }}$ values except between $-1.17 \mu \mathrm{A} / \mathrm{cm}^{2}$ and $-0.37 \mu \mathrm{A} / \mathrm{cm}^{2}$ (Fig. $4 ;-1.17$ and -0.37 corresponded to the 2 Hopf bifurcation points marked a and b). Within this range, the cell exhibited subthreshold oscillations that reached a maximum amplitude of $9.8 \mathrm{mV}$ for $I_{\text {app }}=-0.85$ $\mu \mathrm{A} / \mathrm{cm}^{2}$, and the frequency of these subthreshold oscillations was 5-7 Hz. These values are similar to those recorded in real IO neurons (Benardo and Foster 1986; Lampl and Yarom 1997; Llinás and Yarom 1986).

LOW-THRESHOLD CALCIUM CURRENT. Because the low-threshold calcium current has a central role in IO oscillatory behavior, we examined the variation of $g_{\mathrm{Ca}_{1}-1}$ in our model. We first analyzed the behavior of a cell with $g_{\text {Ca_l }}=1.2 \mathrm{mS} / \mathrm{cm}^{2}$ and compared it to our standard cell $\left(g_{\mathrm{Ca} \_}=1.0 \mathrm{mS} / \mathrm{cm}^{2}\right)$. The relatively small increase in $g_{\mathrm{Ca}_{1} \mathrm{I}}$ resulted in a very different bifurcation diagram (Fig. 5). The cell had multiple stable behaviors, specifically, SS, SO, and R (an example of SS behavior can be seen in Fig. 7D). The spontaneous somatic spiking was between the points marked $\mathrm{a}$ and $\mathrm{b}$ in the figure, which correspond to a large range of input currents $(-1.48-$ $\left.0.19 \mu \mathrm{A} / \mathrm{cm}^{2}\right)$. Between the points $\mathrm{b}$ and c $\left(I_{\text {app }}\right.$ between -0.23 and $0.19 \mu \mathrm{A} / \mathrm{cm}^{2}$ ), the cell had two stable states, either SS or R. This bistability has been observed previously (Bal and McCormick 1997 - see their Fig. $1 B$ for instance). Between the points $\mathrm{c}$ and d, i.e., when $I_{\text {app }}$ was between -0.73 and -0.23
A

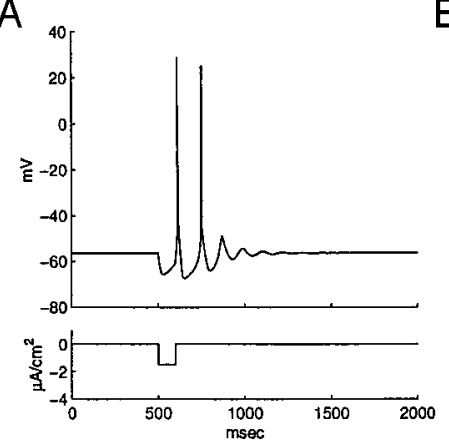

C

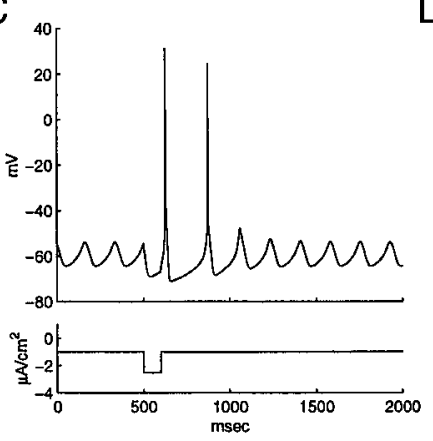

B

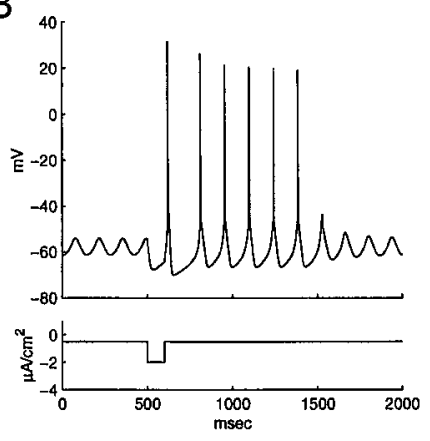

D

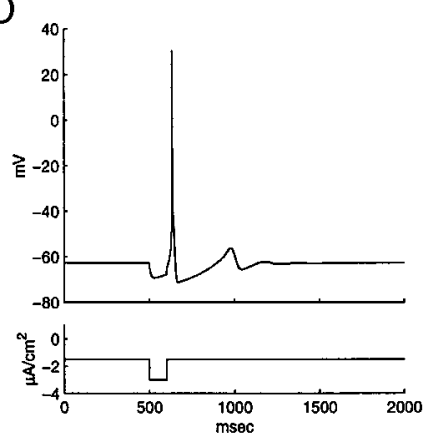

FIG. 3. Response of an IO cell model to a hyperpolarizing somatic current pulse (intensity: $-1.5 \mu \mathrm{A} / \mathrm{cm}^{2}$, duration: $100 \mathrm{~ms}$ ) at different states of tonic hyperpolarization. $A: I_{\text {app }}=0.0 ; B: I_{\text {app }}=-0.5 ; C: I_{\text {app }}=-1.0$; and $D: I_{\text {app }}=$ $-1.5 \mu \mathrm{A} / \mathrm{cm}^{2}$. Cell is most excitable when $I_{\text {app }}=-0.5 \mu \mathrm{A} / \mathrm{cm}^{2}$ and subthreshold oscillations occur only for moderate values of the tonic hyperpolarizing current. 


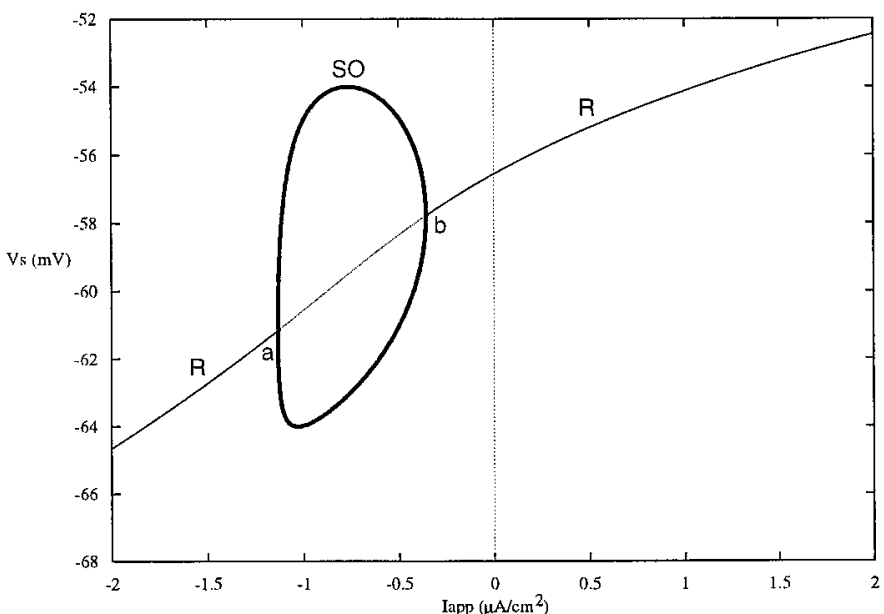

FIG. 4. Bifurcation diagram of the membrane potential $V_{\mathrm{s}}$ as a function of $I_{\text {app }}$, which shows the behavior of the standard cell model as a function of the injected DC current. Cell has a stable steady state for all $I_{\text {app }}$ values except between the points marked $a$ and $b$, where the cell exhibits SO. Thin line: stable steady state. Thin dotted line: unstable steady state. Thick line: stable oscillatory behavior. Hopf bifurcations occur at the thin and thick lines intersections. R, rest. SO, spontaneous subthreshold oscillations.

$\mu \mathrm{A} / \mathrm{cm}^{2}$, the stable behaviors were either subthreshold oscillations or spontaneous somatic spiking. For the domain delimited by the points $\mathrm{d}$ and e ( $I_{\text {app }}$ between -1.30 and -0.73 $\mu \mathrm{A} / \mathrm{cm}^{2}$ ), the only stable state was spontaneous somatic spiking. Finally, the points e and a $\left(I_{\text {app }}\right.$ was -1.47 and -1.30 $\mu \mathrm{A} / \mathrm{cm}^{2}$ ) delimit another zone of bistability, with either subthreshold oscillations or spontaneous spiking. ${ }^{4}$ The frequencies of the spiking oscillations ranged from 3.8 to $9.4 \mathrm{~Hz}$, which is similar to that previously recorded in IO neurons $(4-8 \mathrm{~Hz})$ (Bal and McCormick 1997). The frequencies decreased with stronger hyperpolarization, a result also consistent with previous observations (see Fig. $2 A$ in Bal and McCormick 1997).

Figure 6 illustrates the domains of asymptotic behaviors as a function of both $I_{\text {app }}$ and the maximal conductance $g_{\text {Ca_l }_{1}}$. The oscillations were very sensitive to $g_{\mathrm{Ca}_{\_} \_}$: when $g_{\mathrm{Ca}_{\_} 1}$ was $<0.95$ $\mathrm{mS} / \mathrm{cm}^{2}$, no oscillation occurred for any applied current value. When $g_{\mathrm{Ca} 1}$ was between 1.05 and $2.50 \mathrm{mS} / \mathrm{cm}^{2}$, the SS domain co-existed with the $\mathrm{R}$ domain, for applied currents between -0.75 and $0.15 \mu \mathrm{A} / \mathrm{cm}^{2}$ (bistable SS/R domain). Finally, the spontaneous subthreshold oscillation domain ( $\mathrm{SO}$ ) was small and mostly overlapped with the somatic spiking domain (where the cell is bistable and the domain is described by $\mathrm{SS} / \mathrm{SO}$ in the figure).

h CURRENT. Previous in vitro experiments have shown that $g_{\mathrm{h}}$ is reduced with increasing concentrations of bath-applied $\mathrm{Cs}^{+}$ (Bal and McCormick 1997). To model the effects of $\mathrm{Cs}^{+}, g_{\mathrm{h}}$ was decreased from its standard value $1.5 \mathrm{mS} / \mathrm{cm}^{2}$ (Fig. 7A) to $1.0,0.5$, and $0.0 \mathrm{mS} / \mathrm{cm}^{2}$ (Fig. 7, $B-D$ ), while a tonic current of $-0.5 \mu \mathrm{A} / \mathrm{cm}^{2}$ was applied (note that a hyperpolarizing current pulse of $-1.5 \mu \mathrm{A} / \mathrm{cm}^{2}$ was injected at $500 \mathrm{~ms}$ for $100 \mathrm{~ms}$ to show bistability). The frequency decreased as the conductance value became smaller: it was $\sim 8 \mathrm{~Hz}$ with $g_{\mathrm{h}}=1.5 \mathrm{mS} / \mathrm{cm}^{2}$, and it decreased to $6.2 \mathrm{~Hz}$ when $I_{\mathrm{h}}$ was fully suppressed (frequency analysis conducted with AUTO, data not shown). Similar results have been found in vitro $(\mathrm{Bal}$ and McCormick

\footnotetext{
${ }^{4}$ For a very small range, $-1.477<\mathrm{I}_{\text {app }}<-1.470$, the stable states were the resting state and somatic spiking.
}

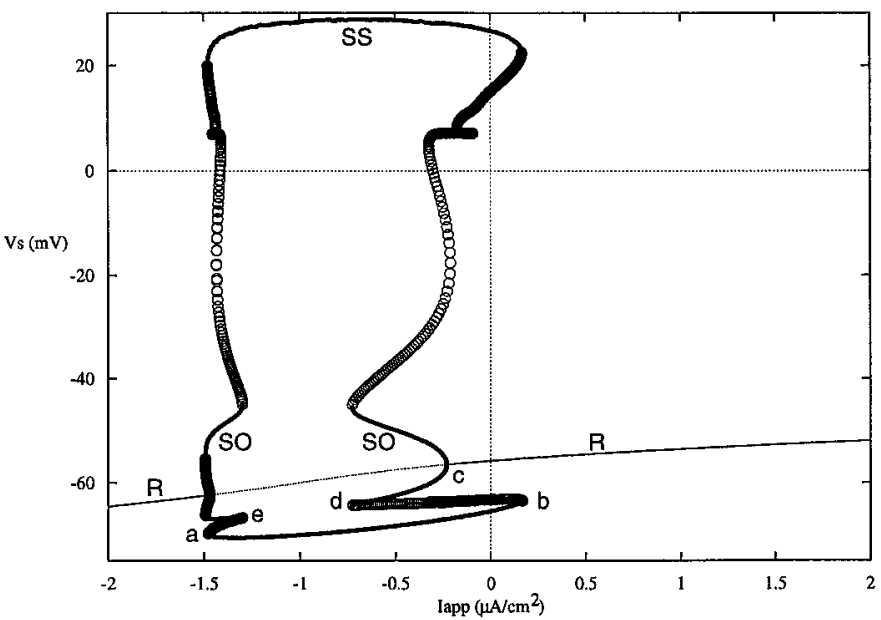

FIG. 5. Bifurcation diagram of the membrane potential $V_{\mathrm{s}}$ as a function of $I_{\text {app }}$, which shows the behavior of a different cell in which $g_{\text {Ca_1 }}$ was changed to $1.2 \mathrm{mS} / \mathrm{cm}^{2}$ (for the standard cell, $g_{\mathrm{Ca}_{-}}=1 \mathrm{mS} / \mathrm{cm}^{2}$ ). Cell now has multiple stable behaviors, namely spontaneous somatic spiking (SS), SO, and R. SS exists between the points $\mathrm{a}$ and $\mathrm{b}$. Between the points $\mathrm{b}$ and $\mathrm{c}$, the cell has two stable states, SS and R. Between the points $\mathrm{c}$ and d, the stable behaviors are either SO or SS. For the range delimited by the points $d$ and e, the only stable state was SS. Finally, the points e and a delimit another bistability zone with either SO or SS. Thin line: stable steady state. Dotted thin line: unstable steady state. Thick lines: stable oscillatory behaviors. Open circles: unstable oscillatory trajectories that are not observable.

1997; see their Fig. 7D). Note also that for $g_{\mathrm{h}}=0.5 \mathrm{mS} / \mathrm{cm}^{2}$ and $g_{\mathrm{h}}=0.0 \mathrm{mS} / \mathrm{cm}^{2}$, the hyperpolarizing pulse generates a dendritic spike. In these cases, as discussed by Yarom and Llinás (1987), somatic and dendritic compartments are effectively more strongly coupled because of higher input resistance: the sodium spike can invade the dendritic compartment enough to generate a dendritic spike.

Next, the effects of systematically varying $g_{\mathrm{h}}$ and $\mathrm{I}_{\text {app }}$ were examined (Fig. 7E). When no current was injected, spontaneous subthreshold oscillations appeared for $g_{\mathrm{h}}<0.67 \mathrm{mS} / \mathrm{cm}^{2}$.

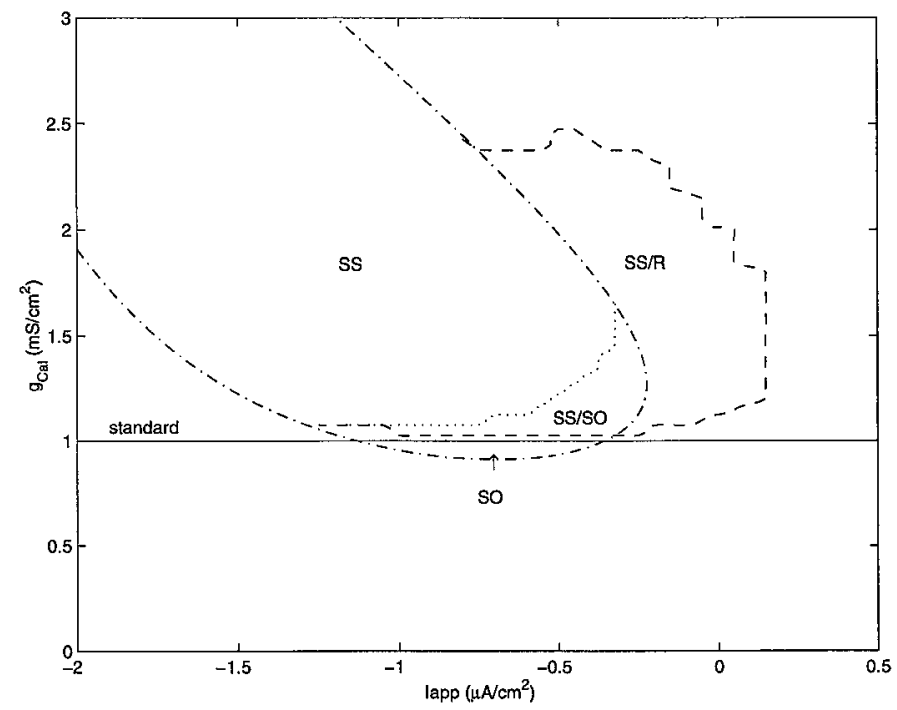

FIG. 6. Response domains when both $g_{\mathrm{Ca}-1}$ and $I_{\mathrm{app}}$ are varied. Note how the low-threshold calcium current is crucial for subthreshold and spiking oscillations. In this figure and in Figs. 7 and 8, the smooth curves were obtained by tracking the bifurcation points with AUTO and the segmented curves were obtained by performing full two parameter searches (see METHODS). 
A

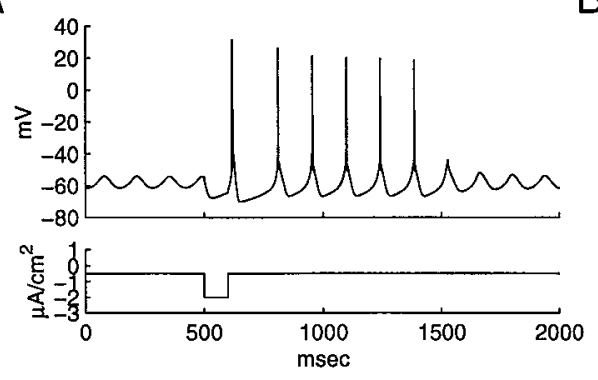

B

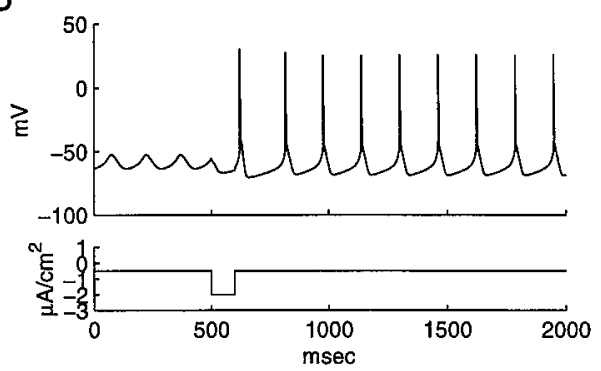

C

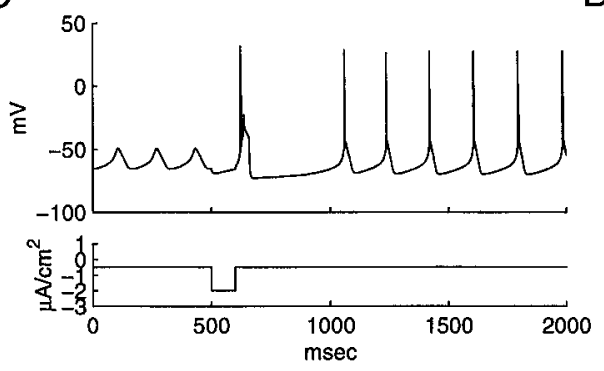

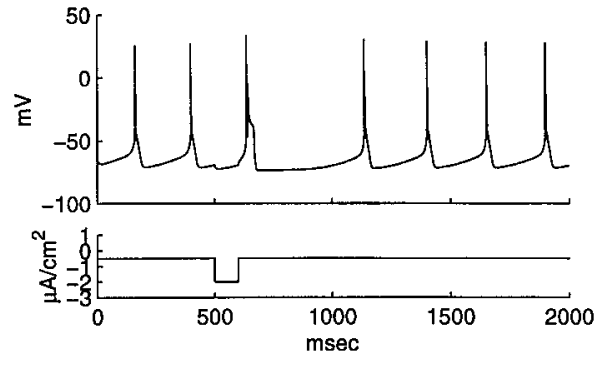

E

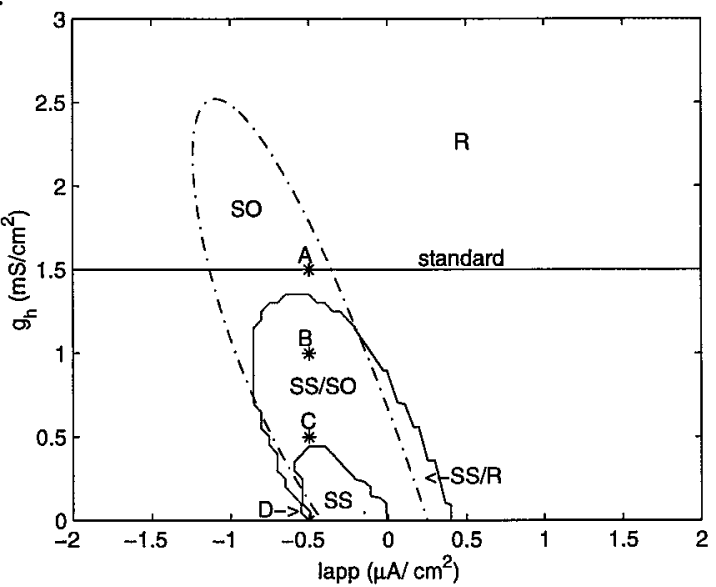

FIG. 7. Effects of varying the conductance of the h current $\left(g_{\mathrm{h}}\right)$ on cell responses. $A: g_{\mathrm{h}}=1.5$ $\mathrm{mS} / \mathrm{cm}^{2} ; B: g_{\mathrm{h}}=1 \mathrm{mS} / \mathrm{cm}^{2} ; C: g_{\mathrm{h}}=0.5 \mathrm{mS} /$ $\mathrm{cm}^{2} ; D: g_{\mathrm{h}}=0 \mathrm{mS} / \mathrm{cm}^{2}$. $I_{\text {app }}$ was held constant at $-0.5 \mu \mathrm{A} / \mathrm{cm}^{2}$; and there is a pulse current injected at $500 \mathrm{~ms}$ (intensity: $-1.5 \mu \mathrm{A} / \mathrm{cm}^{2}$, duration: $100 \mathrm{~ms}$ ). Note the dendritic spike induced by the pulse current in both $C$ and $D$. $E$ : response domains as a function of $g_{\mathrm{h}}$ and $I_{\text {app }}$. Asterisk-labeled points, A, B, C, and D, correspond to conditions in $A, B, C$, and $D$.
For smaller values of the maximal conductance, there was a small range of applied current for which the cell was spontaneous somatic spiking and a larger range for which the cell was bistable (both SS and SO co-existed).

\section{Behavior of two coupled IO cells}

RESPONSES TO A CURRENT PULSE WITH DIFFERENT TONIC CURRENTS. To investigate the effect of coupling on the oscillating behaviors of two cells, we examined the membrane potential of cell 1 as a function of both the tonic input current injected in cell $2\left(I_{\mathrm{app} 2}\right)$, and the coupling conductance $g_{\mathrm{c}}$ (with $\left.I_{\text {app } 1}=0 \mu \mathrm{A} / \mathrm{cm}^{2}\right)$. The cells were "standard cells," except that we set $g_{\mathrm{Ca} 1}=1.2 \mathrm{mS} / \mathrm{cm}^{2}$ to increase the excitability of the cells. The two-parameter diagram (Fig. 8A) shows that for $g_{\mathrm{c}}<$ $0.18 \mathrm{mS} / \mathrm{cm}^{2}$, there were two ranges of $I_{\text {app} 2}$ with subthreshold oscillations. In Fig. $8 A$, to the right of the nearly vertical line (around $I_{\text {app2 }}=-0.2 \mu \mathrm{A} / \mathrm{cm}^{2}$ ), and the area under the curved line, cell 1 was in a stable-steady state. In other regions, the cell oscillated.

Next, in Fig. 8, $B-E$, the membrane potentials of the two cells were plotted for both noncoupled $(C$ and $E$ ) and coupled case ( $B$ and $D: g_{\mathrm{c}}=0.05 \mathrm{mS} / \mathrm{cm}^{2}$ ) for two values of $I_{\mathrm{app} 2}\left(D\right.$ and $E: I_{\mathrm{app} 2}=-1 \mu \mathrm{A} / \mathrm{cm}^{2}$ and $B$ and $C: I_{\mathrm{app} 2}=-4$ $\mu \mathrm{A} / \mathrm{cm}^{2}$ ). A current pulse (intensity: $-1.5 \mu \mathrm{A} / \mathrm{cm}^{2}$, duration: $100 \mathrm{~ms}$ ) was injected in cell 1 at $t=0.5 \mathrm{~s}$. Note how the coupling modifies the cellular responses: In Fig. $8 B$, SO was generated in both cells even though neither of the individual cells was SO before coupling (Fig. 8C). This result is in agreement with the theory according to which the IO is a network of damped oscillators which, when coupled, can generate sustained oscillations (Yarom 1991). It is also consistent with the results of the modeling study of Manor et al. (1997), who showed that, for two cells, it is not necessary for either cell to oscillate spontaneously to obtain sustained oscillations when the cells are coupled. In Fig. 8D, SO could be generated in cell 1 after coupling, even though cell 1 is by itself SS/R (Fig. 8E); also cell 2 became SS/SO instead of SS alone. Note that because the cells are standard cells with $g_{\mathrm{Ca} \_1}=1.2 \mathrm{mS} / \mathrm{cm}^{2}$, the results of Fig. $8 \mathrm{E}$ already have been summarized in Fig. 5 . 
A

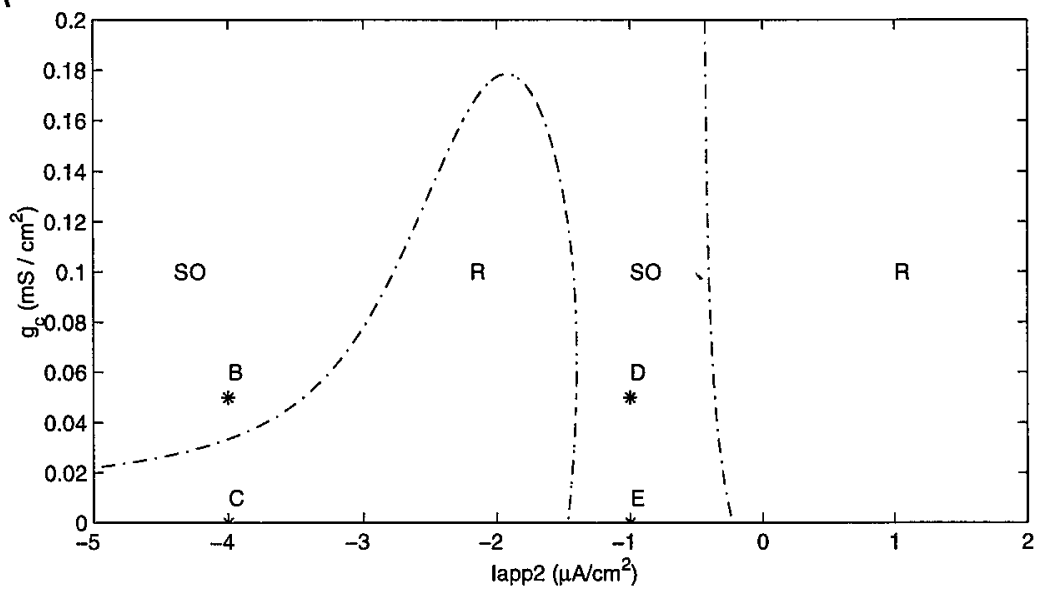

B

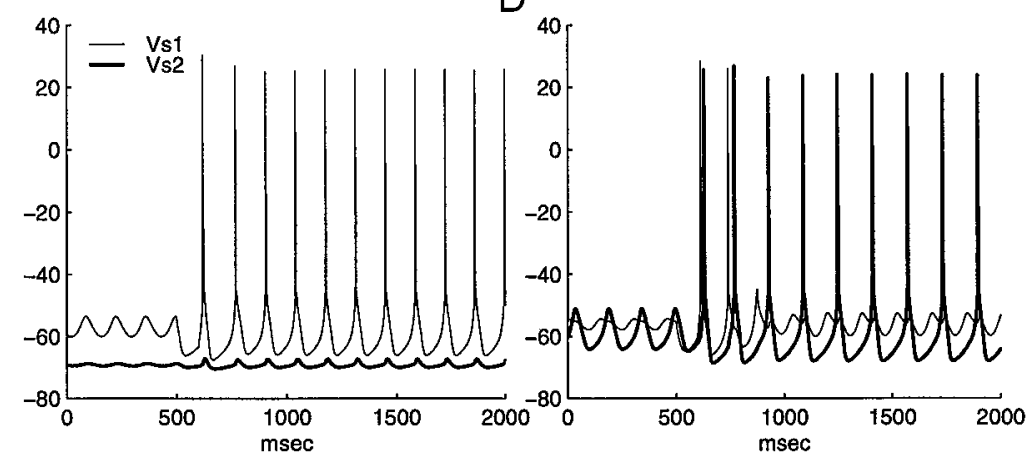

C

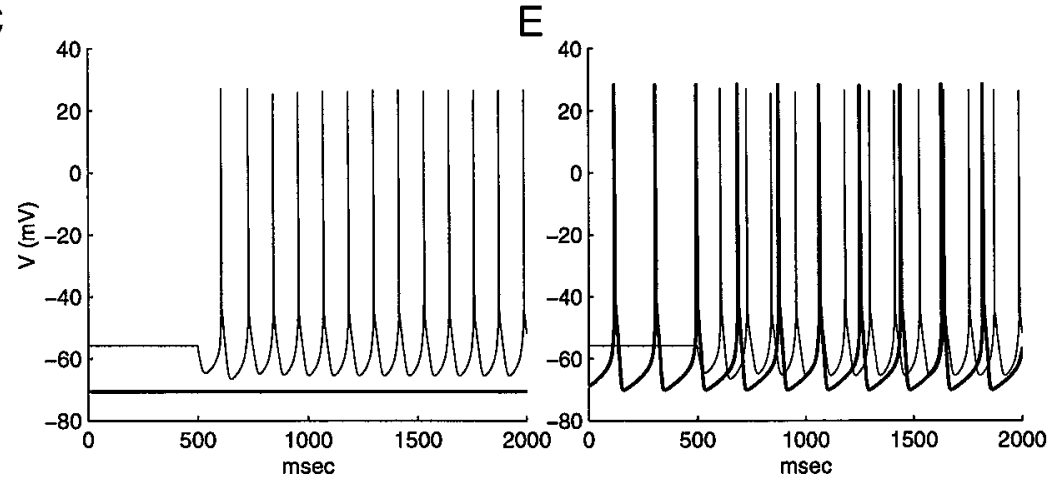

FIG. 8. Oscillatory response of cell 1 as a function of the input current in cell $2, I_{\mathrm{app} 2}$, and $g_{\mathrm{c}}\left(g_{\mathrm{Ca}_{1} 1}=1.2 \mathrm{mS} / \mathrm{cm}^{2}\right.$ and $\left.I_{\text {app } 1}=0 \mu \mathrm{A} / \mathrm{cm}^{2}\right) . A$ : response domains. Note the existence of 2 domains where the cell did not oscillate. $B-E$ : membrane potentials of the 2 cells were plotted for in both noncoupled $(C$ and $E)$ and coupled $(B$ and $D)$ case $\left(g_{\mathrm{c}}=\right.$ $\left.0.05 \mathrm{mS} / \mathrm{cm}^{2}\right)$ for 2 values of $I_{\text {app } 2}\left(I_{\mathrm{app} 2}=-1 \mu \mathrm{A} / \mathrm{cm}^{2}\right.$ and $I_{\text {app2 }}=-4 \mu \mathrm{A} / \mathrm{cm}^{2}$ ). Subplot names $B-E$ correspond to the 4 asterisks in $A$. Thin line: somatic membrane potential of cell 1. Thick line: somatic membrane potential of cell 2. B: $I_{\mathrm{app} 2}=-4.0 \mu \mathrm{A} / \mathrm{cm}^{2}, g_{\mathrm{c}}=0.05 \mathrm{mS} / \mathrm{cm}^{2} ; C: I_{\mathrm{app} 2}=-4.0$ $\mu \mathrm{A} / \mathrm{cm}^{2}, g_{\mathrm{c}}=0.0 \mathrm{mS} / \mathrm{cm}^{2} ; D: I_{\text {app } 2}=-1.0 \mu \mathrm{A} / \mathrm{cm}^{2}, g_{\mathrm{c}}=$ $0.05 \mathrm{mS} / \mathrm{cm}^{2} ; E: I_{\text {app } 2}=-10.0 \mu \mathrm{A} / \mathrm{cm}^{2}, g_{\mathrm{c}}=0.0 \mathrm{mS} / \mathrm{cm}^{2}$. Other details as in Fig. 3.
RESPONSES TO CURRENT PULSES IN SIMULATED HARMALINE APPLICATION CONDITIONS. The drug harmaline is known to induce very robust somatic spiking in IO cells via three pharmacological effects (Llinás and Yarom 1986): it increases the voltage sensitivity of the conductance of the low-threshold calcium current, it hyperpolarizes the cell, and it reduces the anomalous rectification. In simulations, we approximated the increase in voltage sensitivity of the $I_{\mathrm{Ca} \_}$conductance by increasing $g_{\mathrm{Ca} \_}$, the hyperpolarizing effect by injecting a tonic hyperpolarizing current in the soma, and the reduction in $I_{\mathrm{h}}$ by decreasing $g_{\mathrm{h}}$. Thus we set $g_{\mathrm{Ca} \_1}=1.2 \mathrm{mS} / \mathrm{cm}^{2}, I_{\text {app } 1}=$ $I_{\text {app2 }}=-0.8 \mu \mathrm{m} / \mathrm{cm}^{2}$, and $g_{\mathrm{h}}=0.7 \mathrm{mS} / \mathrm{cm}^{2}$ (also we further increased $g_{\mathrm{Na}}$ to $80 \mathrm{mS} / \mathrm{cm}^{2}$ to ensure robust spiking). ${ }^{5}$ The

\footnotetext{
${ }^{5}$ Harmaline shifts the inactivation curve of the low threshold calcium currents to the right (Llinás and Yarom 1986). In the present model, we chose to simulate the modulatory action by adjusting the maximal conductances only, in order not to increase the parameter search space. We did however run
}

cells exhibited strong and robust spontaneous somatic spiking with this set of parameters.

After $g_{\mathrm{c}}$ first was set to $0.03 \mathrm{mS} / \mathrm{cm}^{2}$, a small dendritic pulse was applied to cell $1\left(0.1 \mu \mathrm{A} / \mathrm{cm}^{2}\right.$ for $\left.1 \mathrm{~ms}\right)$. The cells then exhibited nonsynchronous, complex firing patterns, as shown in Fig. 9A. The disparity between the membrane potentials was due to the occurrence of a somatic spike in one cell just before the other cell was to spike. The current flowing from the leading cell to the lagging cell had an effect strong enough to trigger a dendritic spike in the lagging cell (as seen at about $t=$ $0.6 \mathrm{~s})$. As a result, a few nonsynchronous somatic spikes followed in both cells. When the somatic spikes were sufficiently close to each other again, a new dendritic spike was generated in the lagging cell (as seen around $t=2.5 \mathrm{~s}$ in Fig. $9 A$ ), thereby maintaining the complex spiking pattern. The

preliminary simulations which showed that shifting the inactivation function of $\mathrm{I}_{\mathrm{Ca} \_1}$ to the right by $5 \mathrm{mV}$ also reproduced robust somatic spiking. 

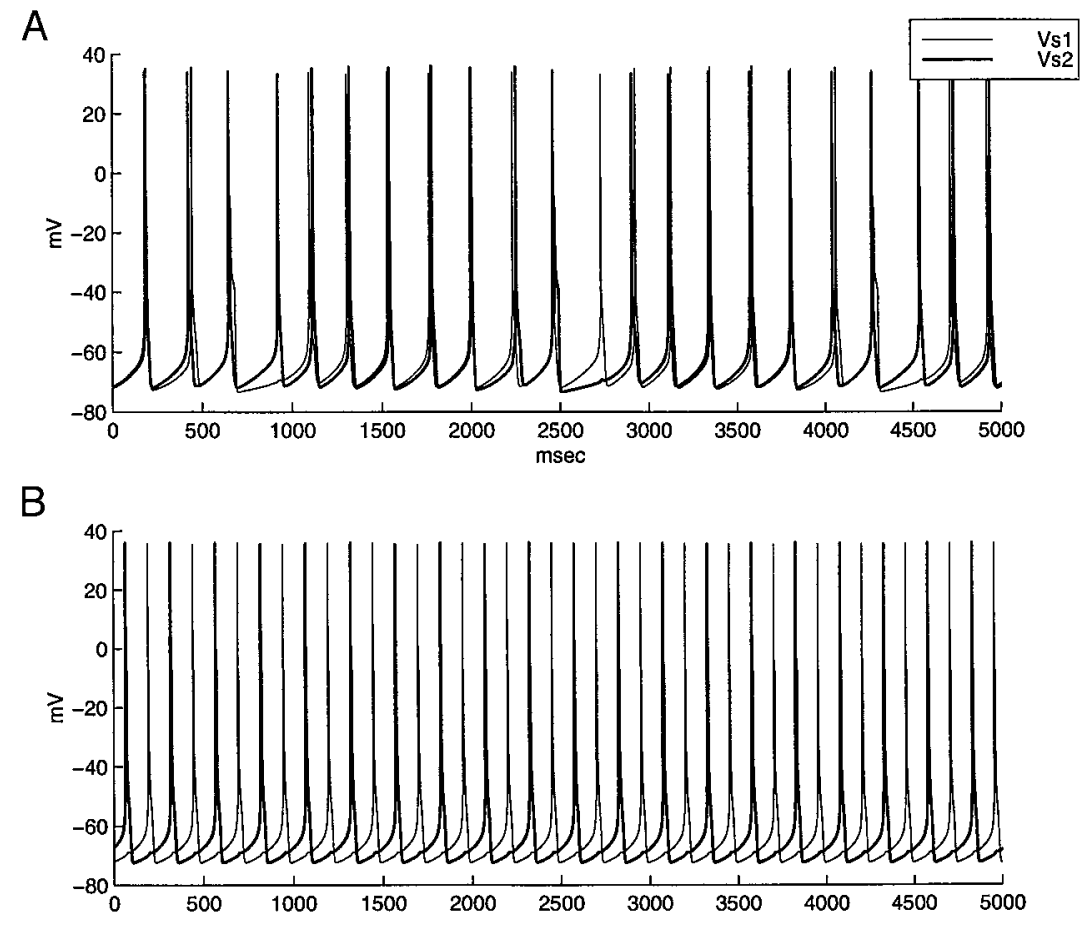

FIG. 9. Responses of coupled spiking cells in 2 conditions. At $t=0.5 \mathrm{~s}$, a depolarizing pulse was given to the dendrite of cell 1 for symmetry breaking. A: complex desynchronized firing patterns obtained for $g_{\mathrm{c}}=0.03 \mathrm{mS} / \mathrm{cm}^{2}, g_{\mathrm{Ca}-1}=1.2$ $\mathrm{mS} / \mathrm{cm}^{2}, g_{\mathrm{h}}=0.7 \mathrm{mS} / \mathrm{cm}^{2}, g_{\mathrm{Na}}=80 \mathrm{mS} / \mathrm{cm}^{2}$, and $I_{\text {app } 1}=$ $I_{\text {app2 }}=-0.8 \mu \mathrm{m} / \mathrm{cm}^{2}$. $B$ : anti-phasic spiking patterns for same parameters as in $A$, except $g_{\text {Ca_1 }}=1.5 \mathrm{mS} / \mathrm{cm}^{2}$ and $g_{\mathrm{c}}=$ $0.01 \mathrm{mS} / \mathrm{cm}^{2}$. For a better visualization of the desynchronization, we plotted cell l's somatic membrane potential vs. cell 2 's potential of for the complex firing pattern case $(C)$ for the anti-phasic case $(D)$.

C
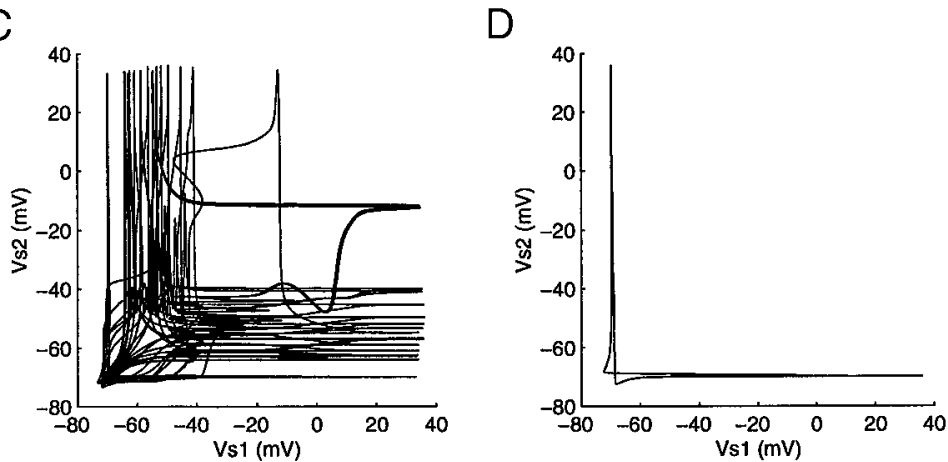

nonsynchronous firing can be better visualized by plotting the membrane potential of cell 1 as a function of the membrane potential of cell 2, as in Fig. $9 C$.

For $g_{\mathrm{c}}=0.01 \mathrm{mS} / \mathrm{cm}^{2}$ and with a further increase in the strength of $I_{\mathrm{Ca} \_1}\left(g_{\mathrm{Ca} \_1}=1.5 \mathrm{mS} / \mathrm{cm}^{2}\right)$, the cells exhibited anti-phasic firing (Fig. 9B). Interestingly, anti-phasic somatic firing has been reported in the IO cells by Llinás and Yarom (1986; see their Fig. 5E). Plotting the membrane potential of one cell as a function of the membrane potential of the other reveals the precise periodicity of this spiking pattern (Fig. 9D).

MODULATION OF BOTH COUPLING STRENGTH AND IONIC CURRENTS IN SIMULATED HARMALINE APPLICATION. Here we show that, in addition to the coupling conductance, the maximal conductance values of both $I_{\mathrm{Ca}_{1} 1}$ and $I_{\mathrm{h}}$ have key roles in the appearance of complex, desynchronized firing patterns. In Fig. $10 A$, the distance $D$ between the two cells is plotted as a function of both $g_{\mathrm{Ca}_{1} 1}$ and $g_{\mathrm{c}}$. The contour $D=2 \mathrm{mV}$ approximately corresponds to the appearance of a significant phase shift. The contour $D=8 \mathrm{mV}$ corresponds to the induction of desynchronizing dendritic spikes by the current flowing through the gap junction (as in Fig. 9A). ${ }^{6}$ Very weak coupling $\left(g_{c}<0.003 \mathrm{mS} / \mathrm{cm}^{2}\right)$ had no effect on the phase relationship of the spiking cells. For a large range of intermediate coupling values ( $g_{\mathrm{c}}$ between 0.003 and $0.15 \mathrm{mS} / \mathrm{cm}^{2}$ ), spiking was complex. Only very large coupling conductances $\left(g_{\mathrm{c}}>0.2\right.$ $\mathrm{mS} / \mathrm{cm}^{2}$ ) brought the two cells into the in-phase mode. Because these large values are probably not biologically plausible (see DISCUSSION), complex firing behavior occurred for almost the whole physiological range of $g_{\mathrm{c}}$. The range of $g_{\mathrm{Ca} \_1}$ for which firing is complex was $1.15-1.4 \mathrm{mS} / \mathrm{cm}^{2}$. This range should be compared with the spontaneous somatic spiking domain: if $g_{\text {Ca_l }}$ was $<0.9 \mathrm{mS} / \mathrm{cm}^{2}$ only subthreshold oscillations were observed, and if $g_{\mathrm{Ca} \_1}$ was $>1.6 \mathrm{mS} / \mathrm{cm}^{2}$, only spontaneous dendritic spiking were observed. Thus desynchronization oc-

\footnotetext{
${ }^{6}$ This value might appear small compared with spike amplitudes. However, since the maximal firing rate is low (around 3-4 spikes per s) and since a sodium spike lasts only a very short time (in the order of $2-3 \mathrm{~ms}$ ), the two desynchronized cells have similar, hyperpolarized, membrane potentials most of the time. During these relatively long-lasting common hyperpolarized phases, the instantaneous distance is small; this explains the small values of the distance, which was temporally averaged over long duration, compared with the spike amplitudes.
} 
A

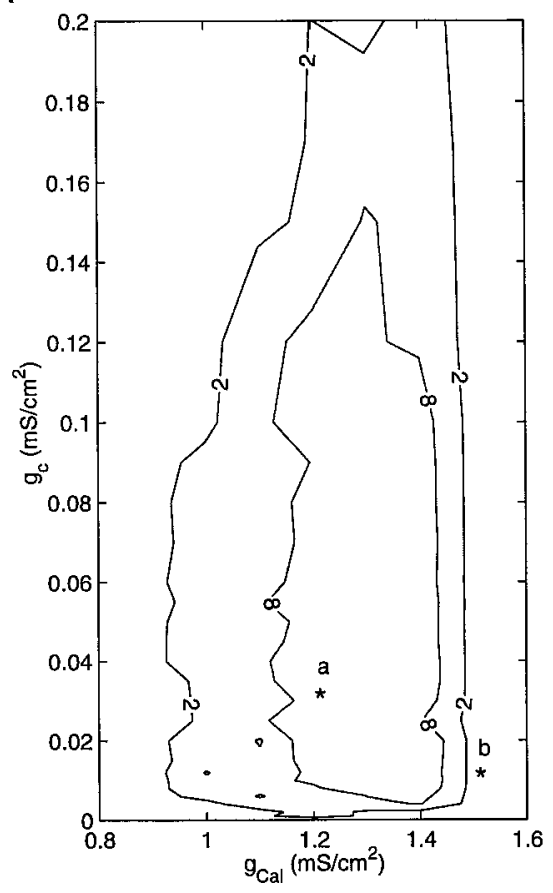

B

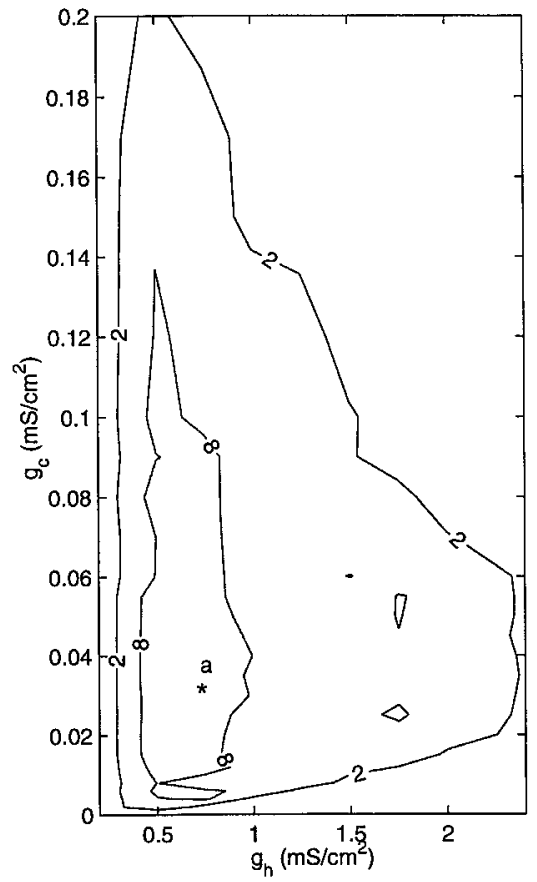

FIG. 10. A: average distance between the 2 cells' membrane potentials as function of both $g_{\mathrm{Ca}_{1}}$ and $g_{\mathrm{c}}$. Contours where the distance $\mathrm{D}$ is $2 \mathrm{mV}$ and $\overline{8} \mathrm{mV}$ are shown $(\mathrm{D}=2 \mathrm{mV}$ approximately corresponds to the appearance of a significant phase shift; $D=8 \mathrm{mV}$ corresponds to the induction of desynchronizing dendritic spikes by the current flowing through the gap junction). The point labeled "a" corresponds to the standard cell under harmaline condition (Fig. 9A) and the point labeled "b" to the anti-phase regime (Fig. 9B). Note how increasing both ionic and coupling conductances tends to desynchronize the cells. B: Distance between the two cells as function of both $g_{\mathrm{h}}$ and $g_{\mathrm{c}}$. As above, very weak coupling had no effect, but for stronger coupling values firing became complex and the two cells were desynchronized. curred for more than a third of $g_{\text {Ca_l }}$ values for which somatic spikes were observed.

In Fig. $10 B$, the distance $D$ between the two cells is plotted as a function of both $g_{\mathrm{h}}$ and $g_{\mathrm{c}}$. As in the preceding text, very weak coupling had no effect, but for stronger coupling values firing became complex, and the two cells were desynchronized. The spiking was complex and desynchronized for a very large range of $g_{\mathrm{c}}$, i.e., $0.005-0.14 \mathrm{mS} / \mathrm{cm}^{2}$ and when $g_{\mathrm{h}}$ was in the $0.4-$ to $1-\mathrm{mS} / \mathrm{cm}^{2}$ range. Thus desynchronization occurred for more than a fourth of possible $g_{\mathrm{h}}$ values. Note that the SS domain was limited to $2.45 \mathrm{mS} / \mathrm{cm}^{2}>g_{\mathrm{h}}>0.25 \mathrm{mS} / \mathrm{cm}^{2}$ : between 0.25 and $0.15 \mathrm{~S} / \mathrm{cm}^{2}$ spontaneous dendritic spiking occurred; $<0.15 \mathrm{mS} / \mathrm{cm}^{2}$ the cells were in a hyperpolarized steady state; and $>2.45 \mathrm{mS} / \mathrm{cm}^{2}$ only subthreshold oscillations were observed. For values of $g_{\mathrm{h}}$ between 0.25 and $0.40 \mathrm{mS} /$ $\mathrm{cm}^{2}$, while one cell is hyperpolarized after a dendritic spike, the other cell could not generate a somatic spike because the depolarization induced by the $\mathrm{h}$ current was weak compared with the hyperpolarizing coupling current. The cells generate a nearly simultaneous somatic spike at the end of the AHP. Therefore in this particular case, dendritic spikes do not lead to significant desynchronization.

\section{I S C U S S I O N}

We propose a novel two-compartment biophysical model of IO neurons that reproduced many reported experimental results. The modeled neurons exhibited multiple firing patterns that depended on the level of depolarization or hyperpolarization, on the relative influence of the ionic currents $I_{\mathrm{Ca} \_1}$ and $I_{\mathrm{h}}$, and on the strength of the electrotonic coupling.

\section{Comparison with related modeling studies}

Two-compartment models similar to the one described here were shown to reproduce successfully many cellular responses of several neurons which contain active dendrites (Booth et al. 1997; Mainen and Sejnowski 1996; Pinsky and Rinzel 1994; Rush and Rinzel 1994). The second compartment, corresponding to the lumped dendrites, allowed us to segregate the soma from the dendritic location of the high-threshold calcium current, the gap junctions, and the synaptic inputs. The morphological parameters $g_{\text {int }}$ and $p$ were critical to the behaviors of the two-compartment model. When the coupling conductance between the two compartment $g_{\text {int }}$ was set to large values (in effect lumping the somatic and dendritic compartments into 1 isopotential compartment), simulations showed that it was impossible to generate somatic spikes: the sodium spikes always triggered dendritic spikes. We found that, for proper functioning of the model $g_{\text {int }}$ must be set to $<0.2 \mathrm{mS} / \mathrm{cm}^{2}$. Moreover, because it is reasonable to assume that intracellular coupling ( $\left.g_{\text {int }}\right)$ is stronger than intercellular coupling $\left(g_{\mathrm{c}}\right)$, we have $g_{\mathrm{c}}<$ $g_{\text {int }}<0.2 \mathrm{mS} / \mathrm{cm}^{2}$ (see Table 2 for plausible ranges of parameters inferred from simulations). In the present model, $p=0.2$ was used for the ratio of the somatic area to the total surface area. In two compartment models, it is difficult, however, to relate directly $p$ to the actual cell morphology due to the attenuation of the current flowing from distal dendrites to the

TABLE 2. Plausible ranges of several parameters inferred from simulations

\begin{tabular}{lc}
\hline \hline \multicolumn{1}{c}{ Parameter } & Range \\
\hline$p$ & $0.2-0.3$ \\
$g_{\text {int }}, \mathrm{mS} / \mathrm{cm}^{2}$ & $0.08-0.2$ \\
$g_{\mathrm{c}}, \mathrm{mS} / \mathrm{cm}^{2}$ & $g_{\mathrm{c}}<g_{\text {int }}$ \\
$g_{\mathrm{Ca} \_1}, \mathrm{mS} / \mathrm{cm}^{2}$ & $0.5-1.5$ \\
$g_{\mathrm{h}}, \mathrm{mS} / \mathrm{cm}^{2}$ & $1-2$ \\
\hline
\end{tabular}

Note how the ranges for the first four parameters have been reduced compared with Table 1. 
soma (Pinsky and Rinzel 1994). Thus $p$ should be larger than the actual morphological ratio (0.1-0.2) (Manor 1995).

In the present study, the calcium dynamics and the kinetics of the $I_{\mathrm{Ca} \_\mathrm{h}}$ and $I_{\mathrm{K}_{-} \mathrm{Ca}}$ currents were borrowed from Traub et al.'s (1991) CA3 hippocampal pyramidal neuron model. These kinetics lead to satisfactory performance of our IO model because most of the results of the present study are in agreement with experimental observations. It is possible, however, that the very low firing frequency of IO neurons in vivo is due to a longer lasting AHP than in the model ( $\sim 350 \mathrm{~ms}$ when no tonic current is injected). When we used the following calcium dynamics equation (instead of Traub et al.'s)

$$
\frac{\mathrm{d}\left[\mathrm{Ca}^{2+}\right]}{\mathrm{d} t}=-1.0 I_{\mathrm{Ca} \_\mathrm{h}}-0.02\left[\mathrm{Ca}^{2+}\right]
$$

then $I_{\mathrm{K}_{\mathrm{Ca}}}$ was activated for a longer period and created an AHP that lasts $\sim 700 \mathrm{~ms}$ (same experimental conditions as in Fig. 2). Thus the maximal firing rate of the cell would be $\sim 1.4$ spikes/s, in line with in vivo data (at most 2 or 3 spikes within a second).

To our knowledge, the model developed by Manor (1995) and Manor et al. (1997) is the only other published model of IO neurons. Their study focused on the subthreshold oscillations, so their model contained only $I_{\mathrm{Ca}_{1} 1}$ and a leakage current (because these 2 currents are sufficient to generate subthreshold oscillations). These authors notably showed that when two nonidentical cells were coupled, oscillations could be generated even though neither of the individual cells was a spontaneous oscillator. For example, the two cells shown in Fig. $8 B$ did not oscillate when they were not coupled because the first cell was too depolarized and the second cell was too hyperpolarized. When coupled (with $g_{\mathrm{c}}=0.05 \mathrm{mS} / \mathrm{cm}^{2}$ ), however, the two cells oscillated at the same frequency, but at different baselines and with a small phase shift. Moreover, if one cell started spiking, the oscillations in the other cell increased in amplitude.

Our model significantly extends the Manor et al. model, however, because we incorporated sodium spikes, dendritic spikes, and AHP. Thus we could investigate the conditions of IO spike generation when input current, electrical coupling strength, and the conductances of both $I_{\mathrm{Ca}_{1} 1}$ and $I_{\mathrm{h}}$ were varied. We further showed that a two-cell network model can exhibit anti-phase spiking (as previously found in simple models of coupled neurons) (e.g., Abarbanel et al. 1996; Kawato et al. 1979; Sherman and Rinzel 1992) and complex, desynchronized firing patterns (also observed in the model of Abarbanel et al. 1996). In the present model, the crucial and novel element is the triggering of dendritic spikes by electrical coupling leading to desynchronization. Our results suggest that this behavior is robust because it can be attained for a large range of coupling and ionic conductances.

Finally, our two-compartment model is complex enough to reproduce the essential properties of IO cells, such as the generation of dendritic and somatic spikes, but computationally simple enough to be later integrated into models of larger networks. Moreover, realistic, time varying inputs could be provided to the IO network by incorporating it into a complete sensorimotor neural system (see Schweighofer et al. 1998).
Ionic current modulation-rhythmicity in single inferior olive cell

As previously described in experiments (Lampl and Yarom 1988; Llinás and Yarom 1986) and in the model of Manor et al. (1997), simulations showed that the low-threshold calcium current had a central role in generating rhythmic behavior. If the maximal conductance of $I_{\mathrm{Ca}_{-} 1}$ was below a threshold value, then spontaneous subthreshold oscillations did not occur regardless of the input current. Small changes in $g_{\mathrm{Ca}-1}$, around the standard cell's parameter had dramatic effects on the cell excitability pattern (R, SO, or SS) as shown in Figs. 5 and 6. Depending on the brain slice, or even depending on the cell impaled, IO neurons recorded in vitro exhibit a variety of responses to the same stimulus, and some cells are more excitable than others. Our results show that even a relatively narrow distribution of $g_{\mathrm{Ca}_{1}}$ in real IO neurons can explain the diversity of responses encountered. Figures 4 and 5 suggest two new experiments to test further the effect of the lowthreshold calcium current in single cells, i.e., cells grown in culture or isolated (this only will be feasible when specific gap junctions blockers become available). In these experiments, both the low-threshold calcium conductance and the injected tonic current are controlled independently. In the first experiment (Fig. 4), starting from rest at the depolarized level, a very slow continuous decrease in the injected tonic current first would produce subthreshold oscillations of increasing amplitudes, then oscillations of decreasing amplitudes, then rest again. In a second experiment (Fig. 5), if the maximal conductance $g_{\mathrm{Ca}_{1} \mathrm{l}}$ is increased (by harmaline for instance), the sequence of responses to decreasing injected current then would be: subthreshold oscillations of increasing amplitudes at slightly hyperpolarized membrane potential, then spontaneous somatic spiking, and finally rest again for large hyperpolarizing currents.

Our results indicate that the anomalous rectifier current $I_{\mathrm{h}}$ plays a major role in controlling the frequency of the oscillatory behavior and the generation of IO somatic spikes. This is consistent with the observations of Bal and McCormick (1997). $I_{\mathrm{Ca} \_}$and $I_{\mathrm{h}}$ play antagonistic roles: while an increase in $g_{\text {Ca_l }}$ makes the cell more excitable (Fig. 6), a decrease in $g_{\mathrm{h}}$ has similar effects (Fig. 7E). The effect of the anomalous rectifier could be tested by controlling simultaneously the conductance of $I_{\mathrm{h}}$ (with serotonin and/or Tris artificial cerebrospinal fluid) (see Bleasel and Pettigrew 1994) and the membrane potentials. For example, an experiment designed to follow a path at a fixed membrane potential similar to $A \rightarrow B \rightarrow C \rightarrow D$ in Fig. 7 could be performed.

In the present model, the frequency of all oscillations are voltage dependent. In agreements with our model, the results of Llinás and Yarom (1986) and of Bal and McCormick (1997)_see their Fig. 2-seem to indicate that somatic spiking oscillations are voltage dependent. However, the spontaneous subthreshold oscillations, in slices where they occur, are voltage independent (Lampl and Yarom 1997; Llinás and Yarom 1986). Part of the discrepancy between our results and these experimental results may be due to network oscillations as opposed to cellular oscillations. Lampl and Yarom (1997) showed that the pattern of subthreshold oscillations is network specific rather than cell specific. Thus injection of current in one cell does not change its oscillatory frequency. Only when 
an experimental method is available to isolate a single IO cell, will it be possible to analyze the voltage dependency of subthreshold oscillations in single cells, as predicted here.

\section{Influence of coupling and current modulation-synchrony and desynchrony of inferior olive cells}

Even though gap junction coupling generally is thought to bring the membrane potential of the two coupled cells closer to each other, we found that, counterintuitively, increasing coupling strength can desynchronize the two spiking cells. If a somatic spike occurred in one cell, a dendritic spike in a coupled cell could be triggered by the current flowing through the gap junctions. Thus under certain conditions, it appears that electrical coupling may induce effects that are similar to those induced by chemical synapses, that is, they may trigger dendritic spikes. In addition, the long AHP after the dendritic spikes increased the complexity of the firing pattern. Desynchronization is robust because there were broad ranges of electrotonic coupling strengths and maximal conductances, $g_{\mathrm{Ca} \_1}$ and $g_{\mathrm{h}}$ where desynchronization was observed. Moreover, we verified that desynchronization does not critically depend on the voltage dependency of the coupling conductance: Linear electrical coupling conductances also can desynchronize the cells (however, because of the stronger overall effect of linear coupling, the range of $g_{\mathrm{c}}$ where desynchronization was observed is smaller). Note that the occurrence of complex firing behavior by a reduction of $g_{\mathrm{h}}$ can be understood by the fact that a reduction of $I_{\mathrm{h}}$ decreases the electrotonic distance between the soma and the dendrites, which, in turn, increases the influence of a somatic spike in one cell on the dendritic compartment of another cell.

It might appear puzzling that because a somatic spike in the leading cell (or cell 1 ) triggers a dendritic spike in the lagging cell (cell 2), electrical coupling fails to trigger a dendritic spike in cell $I$ as well. However, a close inspection of the currents flowing into and out of the two dendritic compartments reveals the following. The cell l's somatic spike propagates in the dendrite and in turn slightly raises the membrane potential of cell 2 . If this happens simultaneously with a rise in the dendritic membrane potential of cell 2 due to the propagation of cell 2's somatic spike, the combined effect is sufficient to trigger a dendritic $I_{\mathrm{Ca} h \mathrm{~h}}$ spike in cell 2 . This, in turn, creates a relatively large current flow through the electrical coupling. However, the somatic spike of cell 1 has already activated the $I_{\mathrm{Ca}}$ current to some extent (but not suffiently to generate a spike), which in turns lead to some activation of $I_{\mathrm{K} \text { Ca }}$. This later current counterbalances the depolarizing effect of the coupling current: As a consequence, no dendritic spike is generated in cell 1 .

To test the effect of coupling on the synchronization, we propose the following experiment: two electrodes could be inserted into two neighboring olivary cells after harmaline application. Because inhibitory inputs from the cerebellar nuclei can decrease significantly the gap junction coupling strength (Lang et al. 1996), excitation or inhibition of deep nuclear cells that project to this region of the IO could be used to control the coupling conductance. We predict that, depending on the electrical coupling strength, the two recorded cells could be in-phase, phase-shifted, anti-phase, or desynchronized.

Our results imply that neuromodulatory inputs to the IO that induce relatively small changes in ionic conductances may bring IO cells into spontaneous rhythmic firing modes and allow neighboring IO cells to be desynchronized. Indeed, serotonin, released by the raphe nucleus, has been shown to have effects very similar to those of harmaline on IO cellular behavior (even though its mode of actions may be different) (Sugihara et al. 1995). Thus it is possible that our results under simulated harmaline application apply to serotonin neuromodulation. First, because only a slight increase in $g_{\mathrm{Ca}_{1}}$ allows spontaneous rhythmic somatic spiking (at least at slightly hyperpolarized membrane potentials), IO cells could be exquisitely sensitive to serotonin: by increasing the voltage sensitivity of $I_{\mathrm{Ca} \_}$, serotonin may allow the control of repetitive spiking. Second, because anomalous rectification is reduced by serotonin (Sugihara et al. 1995), it is possible that $I_{\mathrm{h}}$ plays a central role, along with $I_{\mathrm{Ca}-1}$, in controlling whether the mode of IO cell firing is rhythmic or not in vivo. Moreover, as shown in Fig. 10, both an increase in $I_{\mathrm{Ca}_{1} 1}$ strength and a decrease in $I_{\mathrm{h}}$ strength would make the desynchronization process more likely. This prediction could be tested experimentally by recording two neighboring IO cells and by simultaneously controlling the serotonin level.

\section{A P P E N D I X}

The kinetics equation for the activation and inactivation variables $h$, $n, k, l, q$, and $r$ is

$$
\frac{\mathrm{d} x}{\mathrm{~d} t}=\left[x_{\infty}(V)-x\right] / \tau(V)
$$

Mathematical descriptions of the activation and inactivation functions and their time dependence are given by the following equations.

$I_{N a}$

Adapted from Rush and Rinzel (1994).

$$
\begin{gathered}
m_{\infty}(V)=\frac{\alpha_{m}(V)}{\alpha_{m}(V)+\beta_{m}(V)} \quad \text { with } \quad \alpha_{m}(V)=\frac{0.1(V+41)}{1-\exp [-(V+41) / 10]} \\
\text { and } \quad \beta_{m}(V)=9.0 \exp [-(V+66) / 20] \\
h_{\infty}(V)=\frac{\alpha_{h}(V)}{\alpha_{h}(V)+\beta_{h}(V)} \quad \tau_{h}(V)=\frac{170}{\alpha_{h}(V)+\beta_{h}(V)} \\
\text { with } \quad \alpha_{h}(V)=5.0 \exp [-(V+60) / 15] \\
\text { and } \quad \beta_{h}(V)=\frac{(V+50)}{1-\exp [-(V+50) / 10]}
\end{gathered}
$$

\section{$I_{K_{\_} d r}$}

Adapted from Rush and Rinzel (1994).

$$
\begin{gathered}
n_{\infty}(V)=\frac{\alpha_{n}(V)}{\alpha_{n}(V)+\beta_{n}(V)} \quad \tau_{n}(V)=\frac{5}{\alpha_{n}(V)+\beta_{n}(V)} \\
\text { with } \quad \alpha_{n}(V)=\frac{(V+41)}{1-\exp [-(V+41) / 10]} \\
\text { and } \quad \beta_{n}(V)=12.5 \exp [-(V+51) / 80]
\end{gathered}
$$

$I_{C a \_l}$

Adapted from Manor (1995).

$$
k_{\infty}(V)=\frac{1}{1+\exp [-(V+61) / 4.2]} \quad \tau_{k}=5
$$




$$
l_{\infty}(V)=\frac{1}{1+\exp [(V+85.5) / 8.5]} \quad \tau_{l}(V)=\frac{20 \exp [(V+160) 30]}{1+\exp [(V+84) / 7.3]}+35
$$

$I_{h}$

Adapted from Huguenard and McCormick (1992).

$$
\begin{gathered}
q_{\infty}(V)=\frac{1}{1+\exp [(v+75) / 5.5]} \\
\tau_{q}(V)=\frac{1}{\exp (-0.086 V-14.6)+\exp (0.07 V-1.87)}
\end{gathered}
$$

$I_{C a \_h}$

Adapted from Traub et al. (1991).

$$
\begin{array}{cc}
r_{\infty}(V)=\frac{\alpha_{r}(V)}{\alpha_{r}(V)+\beta_{r}(V)} \quad \tau_{r}(V)=\frac{1}{\alpha_{r}(V)+\beta_{r}(V)} \\
\text { with } \alpha_{r}(V)=\frac{1.6}{1+\exp [-(V-5) / 14]} \quad \text { and } \quad \beta_{r}(V)=\frac{0.02(V+8.5)}{1-\exp [(V+8.5) / 5]}
\end{array}
$$

$I_{K_{-} \mathrm{Ca}}$

Adapted from Traub et al. (1991).

$$
\begin{gathered}
s_{\infty}\left(\left[\mathrm{Ca}^{2+}\right]\right)=\frac{\alpha_{s}\left(\left[\mathrm{Ca}^{2+}\right]\right)}{\alpha_{s}\left(\left[\mathrm{Ca}^{2+}\right]\right)+\beta_{s}} \quad \tau_{s}\left(\left[\mathrm{Ca}^{2+}\right]\right)=\frac{1}{\alpha_{s}\left(\left[\mathrm{Ca}^{2+}\right]\right)+\beta_{s}} \\
\text { with } \alpha_{s}\left(\left[\mathrm{Ca}^{2+}\right]\right)=\min \left(210^{-5}\left[\mathrm{Ca}^{2+}\right], 0.01\right) \text { and } \beta_{s}=0.015
\end{gathered}
$$

The kinetics of the inactivation variable $s$ of $I_{\mathrm{K}_{-} \mathrm{Ca}}$ is given by

$$
\frac{\mathrm{d} s}{\mathrm{~d} t}=\left[s_{\infty}\left(\left[\mathrm{Ca}^{2+}\right]\right)-s\right] / \tau_{s}\left(\left[\mathrm{Ca}^{2+}\right]\right)
$$

In the dendritic compartment, the calcium concentration (assuming no calcium diffusion between compartments) follows the equation

$$
\frac{\mathrm{d}\left[\mathrm{Ca}^{2+}\right]}{\mathrm{d} t}=-3.0 I_{\mathrm{Ca} \_\mathrm{h}}-0.075\left[\mathrm{Ca}^{2+}\right]
$$

$I_{c}$

Adapted from Moreno et al. (1994).

$$
f(V)=0.6 \exp \left(-\frac{V^{2}}{50^{2}}\right)+0.4
$$

The authors thank the anonymous referees for valuable comments and criticisms.

XPPAUT3.0 is available from http://www.pitt.edu/ phase. AUTO is available from http://indy.cs.concordia.ca/auto/. CVODE is available from http:// www.netlib.org/ode/cvode.tar.gz.

Address for reprint requests: N. Schweighofer, ERATO, Kawato Dynamic Brain Project, 2-2, Hikaridai, Seika-cho, Soraku-gun, Kyoto 619-0288, Japan.

Received 10 December 1998; accepted in final form 12 April 1999.

\section{REFERENCES}

Abarbanel, H.D.I., Huerta, R., Rabinovitch, M. I., Rulkov, N. F., Rowat, P. F., AND Selverston, A. I. Synchronized action of synaptically coupled chaotic model of neurons. Neural Comp. 8: 1567-1602, 1996.

BAL, T. AND MCCORMICK, D. A. Synchronized oscillations in the inferior olive are controlled by the hyperpolarization-activated cation current $I_{\mathrm{h}}$. J. Neurophysiol. 77: 3145-3156, 1997.

BenARDo, L. S. AND Foster, R. E. Oscillatory behavior in inferior olive neurons: mechanism, modulation, cell aggregates. Brain Res. Bull. 17: 773-784, 1986.
Bennett, M.V.L. And Versedis, V. K. Biophysics of gap junctions. Semin. Cell. Biol. 3: 29-47, 1992.

Bleasel, A. F. And Pettigrew, A. G. The effect of bicarbonate free artificial cerebrospinal fluid on spontaneous oscillations of the membrane potential in inferior olivary neurons of the rat. Brain Res. 639: 8-20, 1994.

Booth, V., RinZel, J., AND KiEHn, O. Compartmental model of vertebrate motorneurons for $\mathrm{Ca}^{2+}$-dependent spiking and plateau potentials under pharmacological treatment. J. Neurophysiol. 78: 3371-3385, 1997.

Cohen, S. D. AND Hindmarsh, A. C. CVODE User Guide. Lawrence Levermore National Laboratory, 1997.

Condorelli, D. F., Parenti, R., Spinella, F., Salinaro, A. T., Belluardo, N., Cardile, V., AND Cicirata, F. Cloning of a new gap junction gene (Cx36) highly expressed in mammalian brain neurons. Eur. J. Neurosci. 10: 1202-8, 1998.

De Zeeuw, C. I., Holstege, J. C., Ruigrok, T. J., And Voogd, J. Ultrastructural study of the GABAergic, cerebellar, and mesodiencephalic innervation of the cat medial accessory olive: anterograde tracing combined with immunocytochemistry. J. Comp. Neurol. 284: 12-35, 1989.

De Zeeuw, C. I., Lang, E. J., Sugihara, I., Ruigrok, T. J., Eisenman, L. M., Mugnaini, E., AND LlinAS, R. Morphological correlates of bilateral synchrony in the rat cerebellar cortex. J. Neurosci. 16: 3412-3426, 1996.

De Zeeuw, C. I., Simpson, J. I., Hoogenraad, C. C., Galjart, N., KoekKoek, S. K., AND RUIGROK, T. J. Microcircuitry and function of the inferior olive. Trends Neurosci. 21: 391-400, 1998.

DoEDEL, E. J. AUTO: a program for the automatic bifurcation analysis of autonomous systems. Proceedings of the 10th Manitoba Conference on Numerical Mathematics and Computation. Winnipeg: University of Manitoba, 1981 , p. 265-284.

ERMENTROUT, B. XPPAUT3.0-The Differential Equations Toll. University of Pittsburgh, 1997.

Huguenard, J. R. AND MCCORMick, D. A. Simulation of the currents involved in rhythmic oscillations in thalamic relay neurons. J. Neurophysiol. 68: 1373-1383, 1992.

Kawato, M., Sokabe, M., and Suzuki, R. Synergism and antagonism of neurons caused by an electrical synapse. Biol. Cybern. 34: 81-89, 1979.

Keating, J. G. AND Thach, W. T. Non-clock behavior of inferior olive neurons: interspike interval of Purkinje cell complex spike discharge in the awake behaving monkey is random. J. Neurophysiol. 73: 1329-1340, 1995.

Kitazawa, S., Kimura, T., AND Yin, P. B. Cerebellar complex spikes encode both destinations and errors in arm movements. Nature 392: 494-497, 1998.

Kobayashi, Y., Kawano, K., Takemura, A., Inoue, Y., Kitama, T., Gomi, H., AND Kawato, M. Temporal firing patterns of Purkinje cells in the cerebellar ventral paraflocullus during ocular following responses in monkeys. II. Complex spikes. J. Neurophysiol. 80: 832-848, 1998.

KOGAN, A. AND YAROM, Y. Electrotonic coupling in inferior olivary neurons revealed by direct measurements. Soc. Neurosci. Abstr. 507: 5, 1997.

LAMPL, I. AND YAROM, Y. Subthreshold oscillations and resonant behavior: two manifestations of the same mechanism. Neuroscience 78: 325-341, 1997.

Lang, E. J., Sugihara, I., AND Llinás, R. GABAergic modulation of complex spike activity by the cerebellar nucleoolivary pathway in the rat. J. Neurophysiol. 76: 255-275, 1996.

LLINÁs, R., BAKER, R., AND SOTELO, C. Electrotonic coupling between neurons in cat inferior olive. J. Neurophysiol. 37: 560-571, 1974.

LLINÁs, R. AND YAROM, Y. Electrophysiology of mammalian inferior olivary neurons in vitro. Different types of voltage-dependent ionic conductances. J. Physiol. (Lond.) 315: 549-567, 1981a.

LLINÁs, R. AND YAROM, Y. Properties and distribution of ionic conductances generating electroresponsiveness of mammalian inferior olivary neurons in vitro. J. Physiol. (Lond.) 315: 569-584, 1981b.

LLINÁs, R. AND YAROM, Y. Oscillatory properties of guinea pig inferior olivary neurons and their pharmacology modulation: an in-vitro study. J. Physiol. (Lond.) 376: 163-182, 1986

MAINEN, Z. F. AND SEJNOWSKI, T. J. Influence of dendritic structure on firing pattern in model neocortical neurons. Nature 382: 363-366, 1996.

MANOR, Y. Construction of an Experimentally Based Neuronal Network Model to Explore the Function of the Inferior Olive Nucleus ( $\mathrm{PhD}$ thesis). Jerusalem, Israel: Hebrew University, 1995.

Manor, Y., RinZel, J., SEgev, I., AND YaROM, Y. Low-amplitude oscillations in the inferior olive: a model based on electrical coupling of neurons with heterogeneous channel densities. J. Neurophysiol. 77: 2736-2752, 1997. 
Moreno, A. P., Rook, M. B., Fishma, G. I., And Spray, D. C. Gap junction channels: distinct voltage-sensitive and -insensitive conductances states. Biophys. J. 67: 113-119, 1994.

PINSKY, P. F. AND RINZEL, J. Intrinsic and network rhythmogenesis in a reduced Traub model for CA3 neurons. J. Comp. Neurosci. 1: 39-60, 1994.

RinZEL, J. AND ERmentrout, G. B. Analysis of neural excitability and oscillations. In: Methods in Neuronal Modeling, edited by C. Koch and I. Segev. Cambridge, MA: The MIT Press, 1989, p. 135-170.

RuigroK, T. J. AND Voogd, J. Cerebellar influence on olivary excitability in the cat. Eur. J. Neurosci. 7: 679-693, 1995.

Rush, M. E. AND RINZEL, J. Analysis of bursting in a thalamic neuron model. Biol. Cybern. 71: 281-284, 1994.

Sasaki, K., Bower, J. M., And Llinás, R. Multiple Purkinje cell recording in rodent cerebellar cortex. Eur. J. Neurosci. 1: 572-586, 1989.

Schweighofer, N., Spoelstra, J., Arbib, M. A., And Kawato, M. Role of the cerebellum in reaching movements in humans. II. A neural model of the intermediate cerebellum. Eur. J. Neurosci. 10: 95-105, 1998.

SHERmAn, A. AND RinZEL, J. Rhythmogenic effects of weak electrotonic coupling in neuronal models. Proc. Natl. Acad. Sci. USA 89: 2471-2474, 1992.
Simpson, J. I., Wylie, D. R., AND De Zeeuw, C. I. On climbing fiber functions and their consequences. Behav. Brain Sci. 19: 384-398, 1996.

Sotelo, C., Llinás, R., AND BAKER, R. Structural study of inferior olivary nucleus of the cat: morphological correlates of electrotonic coupling. J. Neurophysiol. 37: 541-559, 1974.

Sugihara, I., LANG, E. J., AND LlinÁs, R. Serotonin modulation of inferior olivary oscillations and synchronicity: a multiple-electrode study in the rat cerebellum. Eur. J. Neurosci. 7: 521-534, 1995.

Traub, R. D., Wong, R.K.S., Miles, R., and Michelson, H. A model of a CA3 hippocampal pyramidal neuron incorporating voltage-clamp data on intrinsic conductances. J. Neurophysiol. 66: 635-650, 1991.

WeISS, M. AND PELlet, J. Raphe-cerebellum interactions. II. Effects of midbrain raphe stimulation and harmaline administration on single unit activity of cerebellar cortical cells in the rat. Exp. Brain Res. 48: 171-176, 1982.

YAROM Y. Rhythmogenesis in a hybrid system-interconnecting an olivary neuron to an analog network of coupled oscillators. Neuroscience 44: 263-275, 1991.

YAROM, Y. AND LLINÁs, R. Long term modifiability of anomalous and delayed rectification in guinea pig inferior olivary neurons. J. Neurosci. 7: 11661177, 1987. 